\section{(A) Check for updates}

Cite this: Green Chem., 2021, 23, 2553

Received 29th November 2020, Accepted 24th February 2021

DOI: $10.1039 /$ d0gc04040a

rsc.li/greenchem

\title{
Photochemical reduction of carbon dioxide to formic acid
}

\begin{abstract}
Robin Cauwenbergh (D) and Shoubhik Das (DD *
With the growing awareness of green chemistry, carbon capture and utilization (CCU) has received tremendous attention compared to carbon capture and storage (CCS). Over the past decades, the development of sustainable approaches for converting $\mathrm{CO}_{2}$ to valuable products such as $\mathrm{CO}, \mathrm{HCOOH}, \mathrm{CH}_{3} \mathrm{OH}$, organic carboxylic acids and others has become popular and is of great importance for society. In this review, we particularly focus on the generation of $\mathrm{HCOOH}$ using homogeneous catalysts, such as transition metal complexes and organic dyes, under photocatalytic conditions. This review will give an overview of recent reports on this topic to stimulate further research in this appealing and vast growing research area.
\end{abstract}

\section{Introduction}

Carbon dioxide $\left(\mathrm{CO}_{2}\right)$ emissions into the atmosphere have reached an alarming level of $33.1 \mathrm{Gt}$ in $2020 .{ }^{1,2}$ Various sectors such as transportation, industry, agriculture, power, etc. have contributed unequivocally to the total amount of global $\mathrm{CO}_{2}$ emissions. Among them, coal- and gas-fired power plants contributed $30 \%$ of the global $\mathrm{CO}_{2}$ emission. Therefore, urgent capture and storage of $\mathrm{CO}_{2}$ from different power plants and other sectors is required to avoid further emissions of $\mathrm{CO}_{2}$ into the atmosphere. ${ }^{3}$ This process, which is well-known as carbon capture and storage (CCS), is effective, however, subsequent utilization of $\mathrm{CO}_{2}$ would be even more attractive as $\mathrm{CO}_{2}$ is a non-toxic molecule. ${ }^{4-6}$ The aim of this concept is to use $\mathrm{CO}_{2}$ as a $\mathrm{C} 1$ source for the sustainable syntheses of hydrocarbon fuels, fine chemicals and pharmaceuticals. The whole procedure is now defined as carbon capture, use and storage (CCUS). ${ }^{7}$ However, activation of $\mathrm{CO}_{2}$ is highly challenging due to the highest oxidized form of carbon, which is also thermodynamically stable and kinetically inert. ${ }^{8}$

In nature, activation of $\mathrm{CO}_{2}$ has been achieved by several enzymes, such as carbon monoxide dehydrogenases that reduce $\mathrm{CO}_{2}$ to carbon monoxide (CO) and formate dehydrogenases that produce formic acid or generate a methyl group in a tetrahydrofolate-THF mediated process. ${ }^{9}$ Additionally, $\mathrm{CO}_{2}$ is reduced to sugars using solar energy during photosynthesis. ${ }^{10-12}$ Indeed, the average intensity of the total solar irradiance is about $1366.1 \mathrm{~W} \mathrm{~m}^{-2}$, which provides

ORSY Division, Department, of Chemistry, Universiteit Antwerpen, Campus Groenenborger, Groenenborgerlaan 171, 2020 Antwerpen, Belgium.

E-mail: Shoubhik.Das@uantwerpen.be roughly $4.3 \times 10^{20} \mathrm{~J}$ of energy per hour, which is more than that consumed globally in 1 year $\left(4.1 \times 10^{20} \mathrm{~J}\right) !^{13,14}$

Inspired by photosynthesis, visible light-mediated reductions of carbon dioxide have gained increasing attention and $\mathrm{CO}_{2}$ may be converted to $\mathrm{CO}$, formic acid (FA), methanol, methane, etc. using homogeneous catalysts. ${ }^{15-22}$ Among these products, FA is highly advantageous due to its hydrogen storage capability. ${ }^{23-26}$ Additionally, FA as a chemical or as a preservative is expected to witness a healthy growth, at an estimated CAGR (Compound Annual Growth Report) of 3.74\% during the forecast period of 2019-2024. It should also be noted that 1.137 million metric tons of FA are required per year over the entire world to meet the current demand. ${ }^{27}$ Therefore, the generation of FA in a sustainable way would be highly advantageous to meet the global demand (Fig. 1).

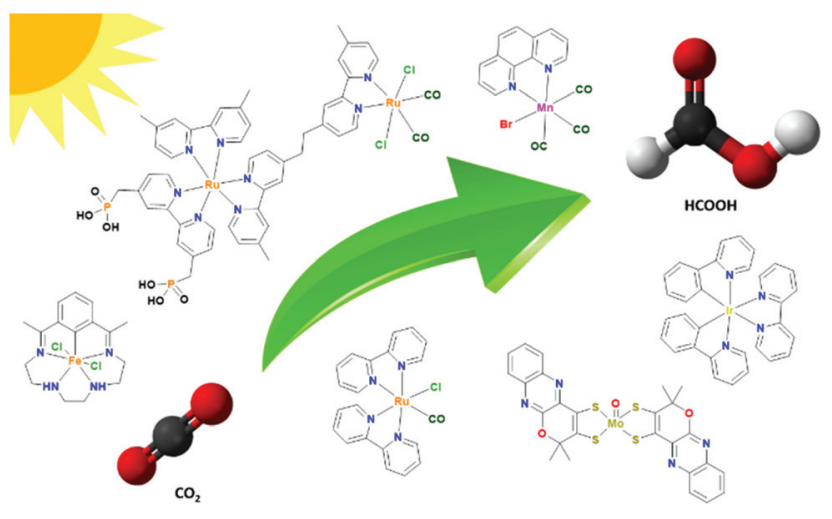

Fig. 1 Transformation of $\mathrm{CO}_{2}$ into formic acid using different transition metal catalysts. 
The first photocatalytic reduction reaction was established by Fujishima et al. using semiconductor based photocatalysis. ${ }^{28-30}$ After that, this research field has made incredible progress. Specifically, new transition metal complexes have been synthesized and applied for the reduction of $\mathrm{CO}_{2}$. In some cases, these metal complexes acted as photosensitisers (PSs) or as photocatalysts (PCs) and in some cases, single metal complexes acted both as PSs and PCs in the photocatalytic reductions of $\mathrm{CO}_{2}$. Considering all these, in this review, we would like to give a summary of the reported homogeneous transition metal complexes and organic dyes for the light-induced reduction of $\mathrm{CO}_{2}$ to FA. In this context, it should be noted that many novel reports exist, which make use of MOFs (Molecular organic framework) or others, however, those articles are beyond this review. ${ }^{31-33}$

\section{Homogeneous $\mathrm{CO}_{2}$ photoreduction}

\section{Ruthenium complexes}

In 1983, Lehn et al. reported for the first time the photocatalytic conversion of $\mathrm{CO}_{2}$ to $\mathrm{CO}$ using a $\mathrm{Re}(\mathrm{bpy})(\mathrm{CO})_{3} \mathrm{X}(\mathrm{X}=$ $\mathrm{Cl}, \mathrm{Br}$ ) catalyst. Although $\mathrm{CO}$ was produced in high selectivity, the generation of $\operatorname{Re}($ bpy $)(\mathrm{CO})_{3}\left(\mathrm{HCO}_{2}\right)$ [bpy $=2,2^{\prime}$-bipyridine] was also observed, which originated from $\mathrm{CO}_{2}$ insertion into the Re-H bond. ${ }^{34}$ Further to their research, Lehn and coworkers reported for the first time the photocatalytic conversion of $\mathrm{CO}_{2}$ to formate using $\mathrm{Ru}(\mathrm{bpy})_{3} \mathrm{Cl}_{2}$ (1) as the photocatalyst in the presence of triethanolamine (TEOA) as the sacrificial oxidant. A turnover number $\left(\mathrm{TON}_{\mathrm{FA}}\right)$ of four was obtained after an irradiation time of 1 hour in the presence of dimethylformamide (DMF) as the solvent. When the solvent was changed to acetonitrile (MeCN), the $\mathrm{TON}_{\mathrm{FA}}$ was lowered to two. Additionally, when the bipyridine (bpy) ligands were changed to 1,10-phenanthroline (phen) ligands, no formate was observed. Further optimizations led to the highest $\mathrm{TON}_{\mathrm{FA}}$ of 27 after irradiating the $\mathrm{CO}_{2}-\mathrm{Ru}(\mathrm{bpy})_{3} \mathrm{Cl}_{2}$-TEOA-DMF mixture for 24 hours. $^{35}$

Lehn et al. continued their research in this area where they initially investigated the effect of $\mathrm{CO}_{2}$ concentration. They found that the generation of formate remained linear over time when $\mathrm{CO}_{2}$ was added regularly, which indicated that $\mathrm{CO}_{2}$ played an important role in the rate determining step. Additionally, they did not find any $\mathrm{CO}_{2}$ pressure effect between $0.5 \mathrm{~atm}$ and $2 \mathrm{~atm}$, but at a higher pressure of $7 \mathrm{~atm}$, the formation of formate decreased drastically. The main reason for this was the increased acidity of the reaction mixture, which made TEOA less efficient as an electron donor since it was in its protonated form. Secondly, the effect of water was investigated. They found that without the addition of water no formate was formed, whereas in the presence of water formate was formed. However, with a large amount of water, more CO and $\mathrm{H}_{2}$ were formed at the expense of formate. Thirdly, they reported the increase of formate formation when an excess of bipyridine ligand was added. A reasonable explanation could be a shift in the tris-bpy complex, the PS, to the bis-bpy complex, the PC, ratio. This explanation was based on the observation of new peaks in NMR spectra at around $8.36 \mathrm{ppm}$, which were most likely coming from $\mathrm{Ru}^{\mathrm{II}}$ bis-bpy species. Based on these observations, Lehn et al. studied the photoreduction of $\mathrm{CO}_{2}$ to formate in the presence of a $\mathrm{Ru}^{\mathrm{II}}$ bis-bpy or a $\mathrm{Ru}^{\mathrm{II}}$ mono-bpy catalyst and a $\mathrm{Ru}^{\mathrm{II}}$ tris-bpy photosensitizer (Table $1 ; 2$ to 8). The highest yield was obtained using [Ru $\left.(\text { bpy })_{2}(\mathrm{CO})(\mathrm{Cl})\right]^{+}(2)$ or $\left[\mathrm{Ru}(\mathrm{bpy})_{2}(\mathrm{CO})(\mathrm{H})\right]^{+}(3)$ as the catalyst with a $\mathrm{TON}_{\mathrm{FA}}$ of 326 or 322 , respectively, after 2 hours of irradiation in the presence of $\mathrm{Ru}(\mathrm{bpy})_{3}$ as the photosensitizer. Remarkably, by adding an excess of bpy ligand, the $\mathrm{TON}_{\mathrm{FA}}$ was dropped from 322 to 245 . $^{36}$

In the same year, Ishida et al. observed that the formate formation was increased drastically with the addition of $\left[\mathrm{Ru}(\mathrm{bpy})_{2}(\mathrm{CO})_{2}\right]^{2+}(5)$ to $\mathrm{Ru}(\mathrm{bpy})_{3}$, which resulted in a $\mathrm{TON}_{\mathrm{FA}}$ of 238 when equimolar amounts of both the complexes were used. In their experiment, $\left[\mathrm{Ru}(\mathrm{bpy})_{3}\right]^{2+}$ was used as the photosensitizer, whereas $\left[\mathrm{Ru}(\mathrm{bpy})_{2}(\mathrm{CO})_{2}\right]^{2+}$ was used as the catalyst. Additionally, $\left[\mathrm{Ru}(\mathrm{phen})_{3}\right]^{2+}$ was also able to reduce $\mathrm{CO}_{2}$ to formate but less efficient than the $\left[\mathrm{Ru}(\mathrm{bpy})_{3}\right]^{2+}$ catalyst. This study revealed that a small amount of formate could be formed under the same conditions of Lehn $e t$ al. due to the generation of bis(bipyridine)ruthenium species by the dissociation of a bpy ligand from the $\left[\mathrm{Ru}(\mathrm{bpy})_{3}\right]^{2+}$ complex. However, when water was added to the reaction mixture, the amount of formate dropped drastically. This can be explained by the decrease of basicity of TEOA which was not suitable as an electron donor due to the conversion to the corresponding protonated form. For this reason, Ishida and co-workers replaced TEOA with 1-benzyl-1,4-dihydronicotinamide (BNAH), since it followed the biological $\mathrm{NAD}(\mathrm{P}) \mathrm{H}$ model in an aqueous medium for $\mathrm{CO}_{2}$ fixation. However, the formate formation was dropped drastically due to the formation of $\mathrm{CO}$ under these conditions. The main problem with the $\mathrm{CO}_{2}-\left[\mathrm{Ru}(\mathrm{bpy})_{3}\right]^{2+}$ $\left[\mathrm{Ru}(\mathrm{bpy})_{2}(\mathrm{CO})_{2}\right]^{2+}$-DMF-TEOA system was its stability, where prolonged irradiation induced catalyst decomposition. Later, they proposed a possible mechanism for the reduction of $\mathrm{CO}_{2}$ to FA. They observed that the catalyst released a CO ligand and accepted two photoelectrons from the photosensitizer to form the $\mathrm{Ru}\left(\mathrm{bpy}^{-{ }^{-}}\right)_{2}(\mathrm{CO})$ intermediate. This intermediate was able to coordinate with a $\mathrm{CO}_{2}$ molecule to form the $\mathrm{Ru}(\mathrm{bpy})_{2}(\mathrm{CO})$ $\left(\mathrm{CO}_{2}\right)$ intermediate. Finally, a proton was added to form $\left[\mathrm{Ru}(\mathrm{bpy})_{2}(\mathrm{CO})(\mathrm{COOH})\right]^{+}$, which accepted two electrons to release FA. ${ }^{37}$ On the other hand, Meyer et al. proposed that $\mathrm{Ru}\left(\mathrm{bpy}^{\cdot-}\right)_{2}(\mathrm{CO})$ was firstly protonated to $\mathrm{Ru}(\mathrm{bpy})_{2}(\mathrm{CO}) \mathrm{H}^{+}$, which then gained an electron from the photosensitizer to form $\mathrm{Ru}(\mathrm{bpy})\left(\mathrm{bpy}{ }^{-}\right)(\mathrm{CO}) \mathrm{H}^{+}$. Here, $\mathrm{CO}_{2}$ was inserted into the $\mathrm{Ru}-\mathrm{H}$ bond to form $\mathrm{Ru}(\mathrm{bpy})\left(\mathrm{bpy}^{\circ-}\right)(\mathrm{CO})(\mathrm{OCHO})$. This complex later gained an electron to release FA. ${ }^{38}$

In 2012, an important role of DMF in the photocatalytic reduction of $\mathrm{CO}_{2}$ to FA was observed by Vos et al. ${ }^{39} \mathrm{DMF}$ was readily hydrolysed to formate, so the quantification of formate from $\mathrm{CO}_{2}$ became difficult in this medium. Later in 2014, Ishida et al. confirmed this by performing experiments under an argon (Ar) atmosphere, which, surprisingly, formed $25 \mu \mathrm{mol}$ of formate. This clearly suggested the partial hydro- 
Table 1 Homogeneous Ru-based photocatalysts for $\mathrm{CO}_{2}$ reduction with an Ir- and Re-based photosensitizer
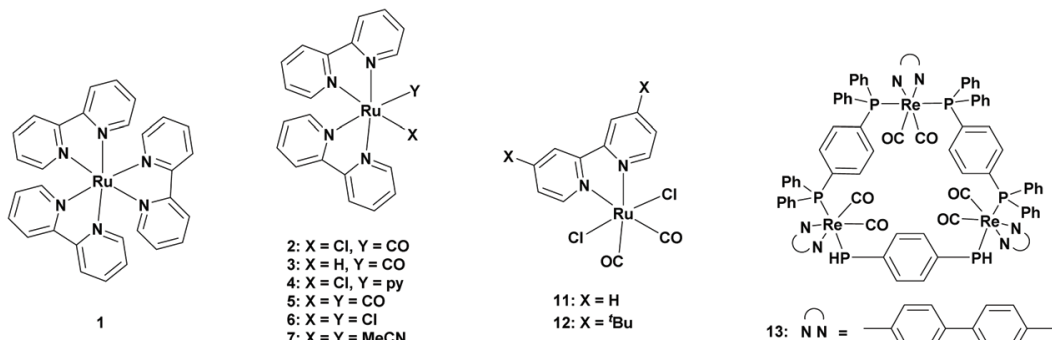

5: $X=Y=C O$
$6: X=Y=C I$
$7: X=Y=M e C N$

7: $X=Y=M e C N$

8: $X=Y=D M F$
9: $X=\mathrm{CO}, Y=\mathrm{H}_{2} \mathrm{O}$

12: $X={ }^{t} B u$
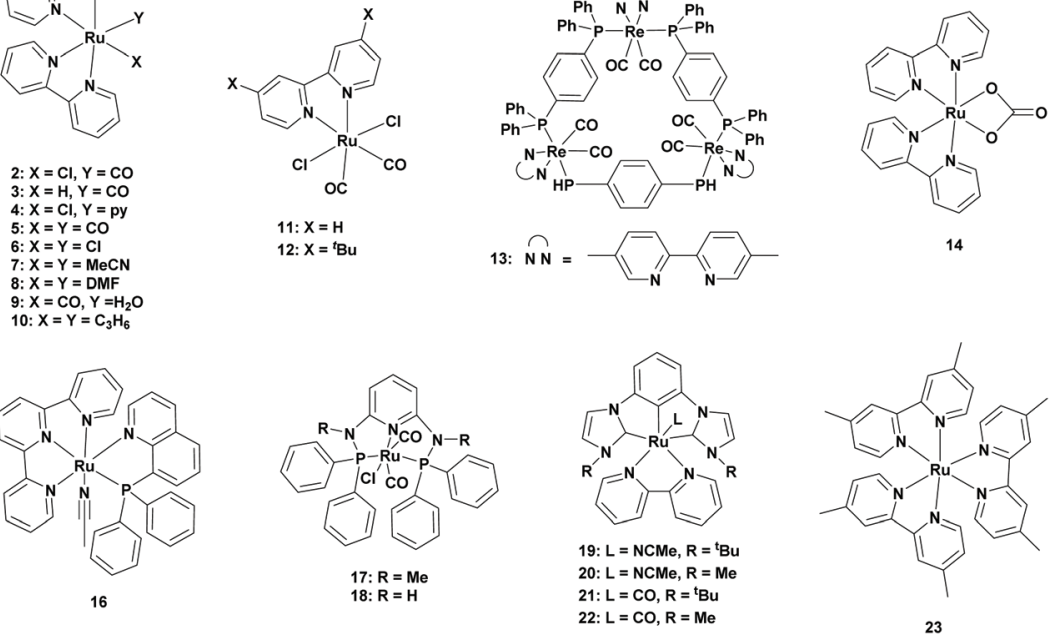

\begin{tabular}{|c|c|c|c|c|c|c|c|c|}
\hline Cat. & PS & SED & Solvent & Irr. $\mathrm{t}(\mathrm{h})$ & Sel. (\%) & $\mathrm{TON}_{\mathrm{FA}}$ & $\lambda(\mathrm{nm})$ & Ref. \\
\hline 1 & N.A. & TEOA & DMF & 24 & $69^{a}$ & 27 & $>400$ & 35 \\
\hline 2 & 1 & TEOA & DMF & 2 & - & 326 & $>400$ & 36 \\
\hline 3 & 1 & TEOA & DMF & 2 & - & 322 & $>400$ & 36 \\
\hline 4 & 1 & TEOA & DMF & 2 & - & 120 & $>400$ & 36 \\
\hline 7 & 1 & TEOA & DMF & 2 & - & 91 & $>400$ & 36 \\
\hline 8 & 1 & TEOA & DMF & 2 & - & 132 & $>400$ & 36 \\
\hline 9 & 1 & TEOA & DMF & 2 & - & 40 & $>400$ & 42 \\
\hline 10 & 1 & TEOA & DMF & 2 & - & 27 & $>400$ & 42 \\
\hline 11 & 1 & TEOA & DMF & 2 & - & 255 & $>400$ & 36 \\
\hline 12 & 13 & TEOA & DMA & 23 & 76 & 290 & 436 & 46 \\
\hline 2 & 15 & TEOA & NMP & 5 & 75 & 62 & $>400$ & 42 \\
\hline 17 & 1 & TEOA & DMF & 24 & $>99$ & 380 & 405 & 49 \\
\hline 18 & 1 & TEOA & DMF & 24 & 83 & 70.5 & 405 & 49 \\
\hline 19 & 23 & $\mathrm{BI}(\mathrm{OH}) \mathrm{H} / \mathrm{TEOA}$ & DMA & 24 & 83 & 3296 & $>500$ & 51 \\
\hline 20 & 23 & $\mathrm{BI}(\mathrm{OH}) \mathrm{H} / \mathrm{TEOA}$ & DMA & 24 & 73 & 4593 & $>500$ & 51 \\
\hline 21 & 23 & $\mathrm{BI}(\mathrm{OH}) \mathrm{H} / \mathrm{TEOA}$ & DMA & 24 & 86 & 3792 & $>500$ & 51 \\
\hline 22 & 23 & $\mathrm{BI}(\mathrm{OH}) \mathrm{H} / \mathrm{TEOA}$ & DMA & 24 & 72 & 5634 & $>500$ & 51 \\
\hline
\end{tabular}

Cat. represents catalyst; PS represents photosensitizer; SED represents sacrificial electron donor; Irr. t represents irradiation time; Sel. represents selectivity; $\mathrm{TON}_{\mathrm{FA}}$ represents turnover number for formic acid generation; $\lambda$ represents wavenumber of incident light; Ref. represents reference; N.A. represents not applicable. Selectivities and TONs were determined after the corresponding irradiation times unless stated otherwise. ${ }^{a}$ Determined after $2.5 \mathrm{~h}$ of irradiation. $-=$ not mentioned.

lysis of DMF. For this reason, Ishida et al. proposed dimethylacetamide (DMA) as an alternative solvent for the reduction of $\mathrm{CO}_{2}$ in the presence of $\left[\mathrm{Ru}(\mathrm{bpy})_{3}\right]^{2+}$ as the photosensitizer, $[\mathrm{Ru}$ $\left.(\text { bpy })_{2}(\mathrm{CO})_{2}\right]^{2+}$ as the catalyst and BNAH as the electron donor. Under these reaction conditions, no precipitation was observed from the dimerized catalysts but the reduction of $\mathrm{CO}_{2}$ to $\mathrm{CO}$ was dominant. ${ }^{40}$ Ishida et al. continued their research in this area. After replacing the previous catalyst to $\operatorname{trans}(\mathrm{Cl})-\mathrm{Ru}(\mathrm{bpy})(\mathrm{CO})_{2} \mathrm{Cl}_{2}$ (Table $1 ; \mathbf{1 1}$ ), they observed that the light intensity and the loading of the catalyst affected the $\mathrm{CO} / \mathrm{HCOO}^{-}$selectivity. However, mixtures of both the products were still observed and $\mathrm{CO}$ remained the major product. ${ }^{41}$

In 2015, Beller et al. reported iridium-based photosensitizers for the photoreduction of $\mathrm{CO}_{2}$ to FA. $N$-Methyl-2-pyrrolidone (NMP) was chosen as the solvent due to its similar behaviour to that of DMF, but it has higher stability. At first, they tried different Ru-based catalysts containing bipyridine ligands. All the Ru catalysts (Table 1; 2, 3, 6, 9, 10 and 14) 
showed reactivity towards the formation of formate, however, Ru-complexes containing associated CO ligands showed higher efficiencies. To observe the structure-activity relationship with the redox properties, they performed cyclic voltammetry of the different catalysts. Ruthenium catalysts without CO ligands showed reduction potentials at lower values, suggesting that the presence of a $\mathrm{CO}$ ligand enhanced the reduction process. In their experiment, $\left[\mathrm{Ru}(\mathrm{bpy})_{2}(\mathrm{CO})(\mathrm{Cl})\right] \mathrm{PF}_{6}$ (2) was the best catalyst, which had a $\mathrm{TON}_{\mathrm{FA}}$ of 62 for a 1:1 PS to PC ratio. Secondly, a study was also performed on the photosensitizer to catalyst ratio, which clearly showed the increase in formate formation as the concentration of the catalyst was decreased. The maximum reactivity was observed at a 16:1 PS to PC ratio with a TON $\mathrm{FA}_{\mathrm{FA}}$ of 419 and a selectivity of $80 \%$ for formate formation. ${ }^{42}$

Ishitani et al. developed a ring-shaped multinuclear $\mathrm{Re}^{\mathrm{I}}$ complex with cis, trans $-\left[\operatorname{Re}(\right.$ bpy $)(\mathrm{CO})_{2}(\mathrm{P}-\mathrm{P})_{2}$ (Table $\left.1 ; 13\right)$ as the repeating unit. This complex is known to have excellent photophysical properties and excellent stability in the excited state and is a stronger oxidant in its excited state compared to the corresponding mononuclear Re complex. ${ }^{43-45}$ In 2016, Ishitani et al. reported the potential of this Re-ring as a photosensitizer in combination with a Ru-based photocatalyst, namely $\operatorname{trans}(\mathrm{Cl})-\mathrm{Ru}(\mathrm{dtbb})(\mathrm{CO})_{2} \mathrm{Cl}_{2}$ (Table $\left.1 ; 12\right)$ (dtbb $=4,4^{\prime}$-di-tertbutyl-2,2'-bipyridine). A typical experiment included the Rubased photocatalyst and the trinuclear Re photosensitizer in an equimolar ratio in a $\mathrm{CO}_{2}$-saturated DMA : TEOA $(5: 1 \mathrm{v} / \mathrm{v})$ solvent mixture. Formate was produced as the major product ( $\mathrm{TON}_{\mathrm{FA}}$ of 290) along with $\mathrm{H}_{2}$ and $\mathrm{CO}$ as the minor products $\left(\mathrm{TON}_{\mathrm{H} 2}\right.$ of 72 and $\mathrm{TON}_{\mathrm{CO}}$ of 20$)$. When a stronger electron donor (1,3-dimethyl-2-(o-hydroxyphenyl)-2,3-dihydro-1 $H$-benzo $[d]$ imidazole, $\mathrm{BI}(\mathrm{OH}) \mathrm{H})$ was added into the solution, no change in $\mathrm{TON}_{\mathrm{FA}}$ was observed but the selectivity of formate formation was increased. It should be noted that most of the photocatalytic systems used a higher amount of photosensitizer than the catalyst to enhance the electron transfer. ${ }^{46}$

All the previously described routes included a system where the catalyst and photosensitizer were separate. A major drawback was the requirement of electron transfer from the photosensitizer to the catalyst, and the efficiency was often not optimal and thus was limited in photocatalysis. To overcome this, Masaoka et al. reported in 2018 a function-integrated system, which acted as both the photosensitizer and the catalyst. Based on their earlier electrochemical studies, they chose $\operatorname{trans}(P, M e C N)-[\mathrm{Ru}(\mathrm{tpy})(\mathrm{pqn})(\mathrm{MeCN})]^{2+}($ Table $1 ; 16)$ (tpy = $2,2^{\prime}: 6^{\prime}, 2^{\prime \prime}$-terpyridine, pqn $=8$-(diphenylphosphanyl)quinoline $)$ as the catalyst. ${ }^{47}$ The photocatalytic reduction of $\mathrm{CO}_{2}$ was performed in a $\mathrm{DMA} / \mathrm{H}_{2} \mathrm{O}(39: 1, \mathrm{v} / \mathrm{v})$ solvent system, which contained 1,3-dimethyl-2-phenyl-2,3-dihydro- $1 H$-benzo[ $d]$-imidazole (BIH) as a sacrificial electron donor. In this case, CO was selectively generated. When the reaction mixture was basified using TEOA as a sacrificial electron donor, formate was very selectively generated with a $\mathrm{TON}_{\mathrm{FA}}$ of $14{ }^{48}$

In 2019, Richeson et al. reported the use of ruthenium PNP pincer complexes as new photocatalysts for the reduction of $\mathrm{CO}_{2} . \mathrm{CO}_{2}$ was photoreduced in the presence of $\left[\mathrm{Ru}\left(\mathrm{k}^{3}-2,6-\right.\right.$
$\left.\left.\left(\mathrm{Ph}_{2} \mathrm{PNMe}\right)_{2}\left(\mathrm{NC}_{5} \mathrm{H}_{3}\right)\right)(\mathrm{CO})_{2} \mathrm{Cl}^{+}\right] \mathrm{Cl}^{-}$(Table $\left.1 ; 17\right)(1 \mathrm{mM})$ as the catalyst, $\left[\mathrm{Ru}(\mathrm{bpy})_{3}\right]\left(\mathrm{PF}_{6}\right)_{2}(1 \mathrm{mM})$ as the photosensitizer and TEOA as the sacrificial electron donor in DMF. Under these conditions, $\mathrm{CO}_{2}$ was selectively photoreduced to formate ( $\mathrm{TON}_{\mathrm{FA}}$ of 90), where $\mathrm{H}_{2}$ was formed as a by-product. By lowering the concentration of both the catalyst and photosensitizer to $25 \mu \mathrm{M}$, the selectivity was increased to $100 \%$, since no $\mathrm{H}_{2}$ was formed, and the $\mathrm{TON}_{\mathrm{FA}}$ was increased to 380 . They also examined the same reaction conditions with $\left[\mathrm{Ru}\left(\mathrm{k}^{3}-2,6-\right.\right.$ $\left.\left.\left(\mathrm{Ph}_{2} \mathrm{PNH}\right)_{2}\left(\mathrm{NC}_{5} \mathrm{H}_{3}\right)\right)(\mathrm{CO})_{2} \mathrm{Cl}^{+}\right] \mathrm{Cl}^{-}$(Table $\left.1 ; 18\right)$ as the catalyst. Similar results were obtained, however a slightly lower efficiency was observed. ${ }^{49}$

In 2020, Arikawa et al. used CNC pincer complexes since they were known to incorporate $\mathrm{CO}_{2} \cdot{ }^{50}$ In their experiment, $\mathrm{CO}_{2}$ was reduced in the presence of the $\mathrm{CNC} \mathrm{Ru}$ catalyst $[\mathrm{Ru}$ $\left.(\mathrm{dmb})_{3}\right]\left(\mathrm{PF}_{6}\right)_{2}(23)\left(\mathrm{dmb}=4,4^{\prime}\right.$-dimethylbipyridine) as a photosensitizer, $\mathrm{BI}(\mathrm{OH}) \mathrm{H}$ as the sacrificial electron donor and DMA/ TEOA as the solvent mixture. Four types of ruthenium complexes bearing a CNC ligand were examined: (I) a CO ligand and a CNC ligand which was substituted by a tert-butyl group (II), a CO ligand and a CNC ligand which was substituted by a methyl group (III), a MeCN ligand and a CNC ligand which was substituted by a tert-butyl group (IV), and a MeCN ligand and a CNC ligand which was substituted by a methyl group. Comparison among them revealed that ruthenium complexes bearing a CO ligand (Table 1; 21 and 22) generated more formate compared to ruthenium complexes bearing a MeCN ligand (Table 1; 19 and 20). Furthermore, having a methyl substituent on the CNC yielded a higher $\mathrm{TON}_{\mathrm{FA}}$ for the formation of formate, however this was at the expense of the selectivity. Among them, $[(\mathrm{MeCNC}) \mathrm{Ru}(\mathrm{bpy})(\mathrm{NCMe})]\left(\mathrm{PF}_{6}\right)_{2} \quad$ (20) and $[(\mathrm{MeCNC}) \mathrm{Ru}(\mathrm{bpy})(\mathrm{CO})]\left(\mathrm{PF}_{6}\right)_{2}$ (22) were the best catalysts, which obtained TON $\mathrm{FA}_{\mathrm{FA}}$ values of 4593 and 5634, respectively. In both cases, a selectivity of $72 \%$ was achieved. ${ }^{51}$

In conclusion, Ru-complexes are the most extensively studied metal centres for the photoreduction of $\mathrm{CO}_{2}$ to formate. As a result, varieties of novel complexes have been synthesized to achieve high reactivity. Although the structureactivity relationship is hard to determine, this diversity can give rise to further investigation of specific ligands on other metals. Additionally, Ru-based catalysts are, until now, the most active and efficient homogeneous photocatalysts for the generation of FA from $\mathrm{CO}_{2}$. However, the selectivity remained a problem, since $\mathrm{CO}$ is formed as a by-product.

\section{Cobalt complexes}

Ruthenium complexes are the well-studied photocatalysts for the reduction of $\mathrm{CO}_{2}$ to FA. However, recent studies have provided more concerns towards Earth abundant metals. In 1998, Neta et al. reported cobalt porphyrin photocatalysts for the photoreduction of $\mathrm{CO}_{2}$. Reductions of $\mathrm{CO}_{2}$ were performed in acetonitrile containing $5 \%$ of triethylamine (TEA). Control experiments clearly proved the formation of $\mathrm{CO}$ and formate from the reduction of $\mathrm{CO}_{2}$. When $1 \times 10^{-5} \mathrm{~mol} \mathrm{~L}^{-1}$ of cobalt tetraphenylporphyrin (Table $2 ; 24, \mathrm{Co}^{\mathrm{II}} \mathrm{TPP}$ ) was used, about $320-360 \times 10^{-5} \mathrm{~mol} \mathrm{~L}^{-1}$ of formate was generated under their 
Table 2 Homogeneous Co-based photocatalysts for $\mathrm{CO}_{2}$ to FA reduction with a Ru-based, an organic dye and a semiconductor photosensitizer

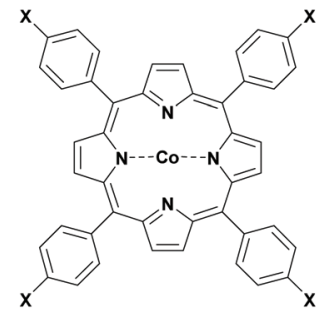

24: $X=H$
25: $X=F$

26: $\mathrm{X}=\mathrm{CF}_{3}$
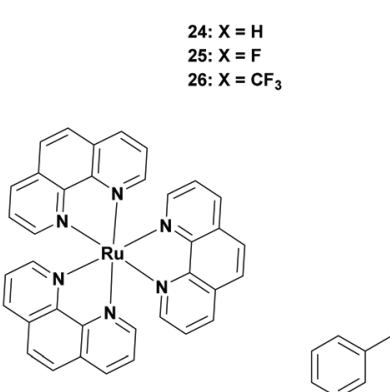

31

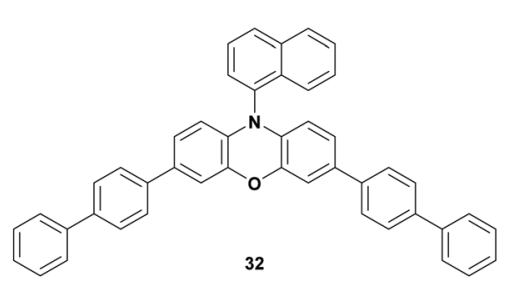

28: NMe group on 3 position
29: NMe group on 4 position

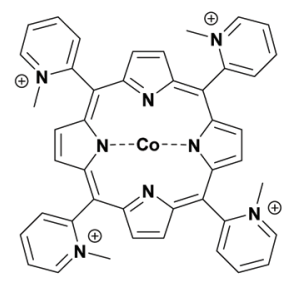

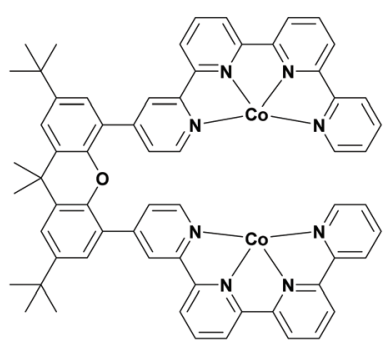

30

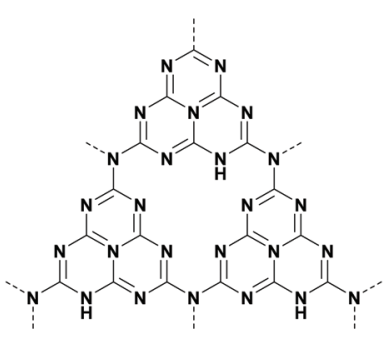

33

\begin{tabular}{|c|c|c|c|c|c|c|c|}
\hline Cat. & PS & SED & Solvent & Sel. (\%) & $\mathrm{TON}_{\mathrm{FA}}$ & $\lambda(\mathrm{nm})$ & Ref. \\
\hline 24 & N.A. & TEA & MeCN & $>80$ & $>245$ & $<320$ & 52 \\
\hline 25 & N.A. & TEA & MeCN & - & $>120$ & $<320$ & 52 \\
\hline 26 & N.A. & TEA & MeCN & - & $>120$ & $<320$ & 52 \\
\hline 27 & N.A. & TEA & MeCN & - & $>120$ & $<320$ & 52 \\
\hline 28 & N.A. & TEA & $\mathrm{MeCN}$ & - & $>120$ & $<320$ & 52 \\
\hline 29 & N.A. & TEA & $\mathrm{MeCN}$ & - & $>120$ & $<320$ & 52 \\
\hline 30 & 31 & TEA & MeCN & 92 & 110 & 460 & 55 \\
\hline 30 & 31 & BIH/TEA & $\mathrm{MeCN}$ & 97 & 386 & 460 & 55 \\
\hline 30 & 31 & BIH/TEOA & MeCN & 76 & 821 & 460 & 55 \\
\hline 30 & 32 & BIH/TEOA & MeCN & 58 & 565 & 460 & 55 \\
\hline 30 & 33 & BIH/TEOA & $\mathrm{MeCN}$ & 91 & 493 & 460 & 55 \\
\hline
\end{tabular}

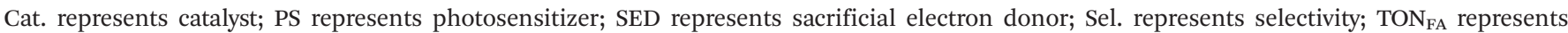

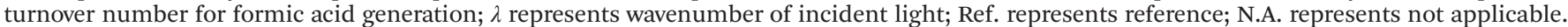
Selectivities and TONs were determined after the corresponding irradiation times unless stated otherwise. $-=$ not mentioned.

reaction conditions. However, $\mathrm{CO}$ was also produced to a lesser extent, which contributed to a total $\mathrm{TON}_{\mathrm{FA}}$ of $>300$ for the $\mathrm{Co}^{\mathrm{II}} \mathrm{TPP}$ catalyst. Derivatives of the $\mathrm{Co}^{\mathrm{II}} \mathrm{TPP}$ catalyst were also examined and the yields of formate using $\mathrm{CoT}_{3} \mathrm{FPP}$ (Table 2; 25), $\mathrm{CoT}_{3} \mathrm{CF}_{3} \mathrm{PP}$ (Table 2; 26) or $\mathrm{CoTM}_{2} \mathrm{PyP}$ (Table 2; 27, $\mathrm{TM}_{2} \mathrm{PyP}=$ tetrakis $(N$-methyl-2-pyridyl)porphyrin $)$ as the photocatalyst were lowered by a factor of two. Comparatively, the yield was drastically lowered when $\mathrm{CoTM}_{3} \mathrm{PyP}$ (Table 2; 28, $\mathrm{TM}_{3} \mathrm{PyP}=$ tetrakis( $N$-methyl-3-pyridyl)porphyrin $)$ and $\mathrm{CoTM}_{4} \mathrm{PyP}$ (Table 2; 29, $\mathrm{TM}_{4} \mathrm{PyP}=\operatorname{tetrakis}(N$-methyl-4-pyridyl) porphyrin) were examined. In all these cases, the porphyrin macrocycle was decomposed which resulted in low efficiency of these photocatalysts. ${ }^{52}$

To solve this problem, Neta et al. continued their research where porphyrin complexes were replaced by corrin complexes. It has been shown that Co-corrins are more stable than Co-porphyrins due to the reduced tendency for protonation on the corrin ring. ${ }^{53}$ Although comparison with their previous studies was not possible since Co-corrins were insoluble in acetonitrile, they performed parallel experiments with CoTPP and hydroxocobalamin (vitamin $\mathrm{B}_{12}$ ) in acetonitrile/methanol $(9: 1, v / v)$ containing $5 \%$ TEA for direct comparison. In both of these experiments, CO was produced in the early stage, whereas formate was produced after longer irradiation. In the case of the corrin catalyst, seven times more formate was produced than when using the porphyrin catalyst. In addition, they observed that when $3 \mathrm{mmol} \mathrm{L}^{-1}$ of $p$-terphenyl (TP) was added as a PS, the yield was increased by a factor of three. This can be explained by the effective photoreduction of TP* by TEA to produce the $\mathrm{TP}^{\cdot-}$ radical anion, which in turn reduced the Co-corrins very efficiently. The main disadvantage of this catalytic system was that Co-corrins could also react with protons to form hydrogen gas, which reduced the corrin macrocycle itself. Although this reduced Co-corrin was able to catalyse the reduction reactions, it bound with $\mathrm{CO}$ which lowered the catalytic activity over time. ${ }^{54}$

Later, in 2019, inspired by the multi-metallic catalytic complexes in nature, Robert et al. used cooperative metal systems for the selective production of formate. To their observation, a binuclear Co complex with a bi-quarterpyridine ligand 
$\left(\left[\mathrm{Co}_{2}(\text { biqpy) }]^{4+}\right.\right.$ (Table 2; 30), biqpy $=4,4^{\prime \prime \prime \prime}$-(2,7-di-tert-butyl-9,9dimethyl-9H-xanthene-4,5-diyl) di-2,2':6',2":6", $2^{\prime \prime \prime}$-quarter-pyridine) was able to reduce $\mathrm{CO}_{2}$ selectively to formate with a high $\mathrm{TON}_{\mathrm{FA}}$. Experiments were carried out using $\left[\mathrm{Co}_{2}(\text { biqpy) }]^{4+}\right.$ as the catalyst and $\left[\mathrm{Ru}(\text { phen })_{3}\right]^{2+}$ (Table $2 ; 31$ ) as the photosensitizer in the presence of a sacrificial reductant in acetonitrile. In the presence of TEA ( $20 \mathrm{vol} \%)$ as the electron donor, formate was generated with $92 \%$ selectivity with a $\mathrm{TON}_{\mathrm{FA}}$ of 110 . The selectivity and $\mathrm{TON}_{\mathrm{FA}}$ were increased to $96.5 \%$ and 386 , respectively, when BIH was added to the solvent mixture. Moreover, the $\mathrm{TON}_{\mathrm{FA}}$ was increased even more to 821 when TEA/BIH was replaced by TEOA/BIH. However, the selectivity was dropped to $75.9 \%$. In a second stage, Robert et al. investigated these optimized reaction conditions with cheaper sensitizers such as organic dyes or graphitic carbon nitrides $\left(\mathrm{g}^{-} \mathrm{C}_{3} \mathrm{~N}_{4}\right)$. In the presence of the phenyl chromophore (Table 2; 32), the $\mathrm{TON}_{\mathrm{FA}}$ and the selectivity were dropped to 565 and $59 \%$, respectively. For $\mathrm{g}^{-} \mathrm{C}_{3} \mathrm{~N}_{4}$ (Table 2 ; 33 ) the selectivity remained almost the same (91\%), but the $\mathrm{TON}_{\mathrm{FA}}$ decreased to $493 . .^{55}$

In conclusion, Co-complexes were the first transition metal complexes used for the photoreduction of $\mathrm{CO}_{2}$ to FA. The main advantage of these complexes is their cheaper price due to high availability in the Earth's crust. Although only a few Co-complexes have been reported, it can be said that they possess moderate to good activities towards the reduction of $\mathrm{CO}_{2}$ to FA. To further enhance the momentum in this direction, ligand diversity should be thoroughly investigated.

\section{Manganese complexes}

In 2014, Ishitani et al. replaced the precious metal complexes with a manganese complex. The research was based on the report of Deronzier et al., where fac- $\mathrm{Mn}(\mathrm{bpy})(\mathrm{CO})_{3} \mathrm{Br}$ (Table 3; 34) was successfully used as an electrocatalyst for the reduction of $\mathrm{CO}_{2}$ to $\mathrm{CO}^{56}$ Ishitani et al. performed the photocatalytic reduction of $\mathrm{CO}_{2}$ using this catalyst $(0.05 \mathrm{mM})$ in the presence of $\left[\mathrm{Ru}(\mathrm{dmb})_{3}\right]^{2+}$ (Table $\left.1 ; 23\right)$ as the photosensitizer and BNAH $(0.1 \mathrm{M})$ as a reductant in a $4: 1(\mathrm{v} / \mathrm{v})$ DMF: TEOA solvent mixture under a $\mathrm{CO}_{2}$ atmosphere. Remarkably, $29.8 \mu \mathrm{mol}$ of formate was formed (TON $\mathrm{FA}_{\mathrm{FA}}$ of 149$)$ with a selectivity of $85 \%$ after $12 \mathrm{~h}$. When the reaction mixture was changed to a $4: 1(\mathrm{v} / \mathrm{v})$ ratio of DMA: TEOA, the $\mathrm{TON}_{\mathrm{FA}}$ dropped to 98 with similar selectivity. In a MeCN : TEOA solvent mixture, not only the $\mathrm{TON}_{\mathrm{FA}}$ was dropped to 78 , but the selectivity was also dropped and a higher amount of $\mathrm{CO}$ was formed. Changing the photosensitizer to $\left[\mathrm{Ru}(\mathrm{bpy})_{3}\right]^{2+}$ increased the $\mathrm{TON}_{\mathrm{FA}}$ slightly to 157 , without changing the selectivity. UV-VIS studies revealed new absorption peaks at $\lambda_{\max }=630 \mathrm{~nm}$ and $820 \mathrm{~nm}$ after the start of the irradiation. The changes in the IR spectrum supported the formation of the $\left[\mathrm{Mn}(\mathrm{bpy})(\mathrm{CO})_{3}\right]_{2}$ dimer. This could be explained by the selective photoexcitation of $\left[\mathrm{Ru}-(\mathrm{dmb})_{3}\right]^{2+}$, which was reductively quenched by BNAH to give $\left[\mathrm{Ru}(\mathrm{dmb})_{2}\left(\mathrm{dmb}^{--}\right)\right]^{+}$. From this state, an electron transfer process proceeded to the Mn-photocatalyst to release $\mathrm{Br}^{-}$for the rapid formation of the Mn dimer. Within 30 minutes, this dimer disappeared, which enhanced the formation of formate and the formation of $\mathrm{CO}$ diminished. The active catalyst for the reduction of $\mathrm{CO}_{2}$ to formate was not clarified but it was proposed to be the five-coordinated manganese radical species $\left[\mathrm{Mn}(\mathrm{bpy})(\mathrm{CO})_{3}\right]^{7}$, which resulted from homolytic dimer cleavage. ${ }^{57}$

Later, Kubiak et al. have substituted the $\mathrm{Br}^{-}$ligand with the pseudohalogen cyanide $\left(\mathrm{CN}^{-}\right)$ligand. Electrocatalytic behaviour was proven to reduce $\mathrm{CO}_{2}$ to $\mathrm{CO}$ to a large extent with a faradaic yield close to $100 \%$. The same study revealed that the $\mathrm{CN}^{-}$ligand did not readily dissociate from the Mn-based electrocatalyst. As a result, the dimer was not obtained as an intermediate for the formation of the active catalyst $[\mathrm{Mn}(\mathrm{bpy})$ $\left.(\mathrm{CO})_{3}\right]^{\circ}$ radical. Instead, the slightly different active catalyst $\left[\mathrm{Mn}(\mathrm{bpy})(\mathrm{CO})_{3}\right]^{-}$anion was generated by a disproportionation reaction. This triggered the research for using this electrocatalyst as a photocatalyst to observe the selectivity pattern in the photoreduction of $\mathrm{CO}_{2}$. Typical experiments were conducted using fac-Mn(bpy) $(\mathrm{CO})_{3}(\mathrm{CN})$ (Table $\left.3 ; 35\right)$ as the photocatalyst, $\left[\mathrm{Ru}(\mathrm{dmb})_{3}\right]^{2+}$ as a photosensitizer and BNAH as a sacrificial reductant in a $4: 1(\mathrm{v} / \mathrm{v})$ DMF : TEOA solvent mixture under a $\mathrm{CO}_{2}$ atmosphere. A maximum $\mathrm{TON}_{\mathrm{FA}}$ of 127 was obtained using $0.10 \mathrm{mM}$ of the photocatalyst, $1.00 \mathrm{mM}$ of the photosensitizer and $0.1 \mathrm{M}$ of the reductant after the irradiation of 15 h. Remarkably, when the solvent mixture was changed to $4: 1(\mathrm{v} / \mathrm{v}) \mathrm{MeCN}$ : TEOA, a decrease of formate was observed $\left(\mathrm{TON}_{\mathrm{FA}}\right.$ of 9), whereas $\mathrm{CO}$ became the major reduction product $\left(\mathrm{TON}_{\mathrm{CO}}\right.$ of 21$)$. It was noted that $f a c-\mathrm{Mn}(\mathrm{bpy})(\mathrm{CO})_{3}(\mathrm{CN})$ underwent a disproportionation reaction under photocatalytic conditions. First, the photosensitizer was photoexcited and was reduced by BNAH to form $\left[\mathrm{Ru}(\mathrm{dmb})_{3}\right]^{\circ+}$. This species transferred an electron to the Mn-based photocatalyst to form a $\left[\mathrm{Mn}(\mathrm{CN})(\mathrm{bpy})^{-}(\mathrm{CO})_{3}\right]^{]^{--}}$radical anion. Two equivalents of this radical anion underwent a disproportionation reaction to yield the active photocatalyst $\left[\mathrm{Mn}(\mathrm{bpy})(\mathrm{CO})_{3}\right]^{-}$and $f a c-\mathrm{Mn}(\mathrm{bpy})$ $(\mathrm{CO})_{3}(\mathrm{CN})$ was regenerated. Later, it has been found that the $\left[\mathrm{Mn}(\mathrm{CN})(\mathrm{bpy})^{-}(\mathrm{CO})_{3}\right]^{--}$intermediate was not stable in $\mathrm{MeCN}$, which provided a possible clarification for the low formation of formate in MeCN. ${ }^{58}$

The photocatalytic reduction of $\mathrm{CO}_{2}$ using Mn-based photocatalysts was best performed in DMF as the solvent. However, DMF is a toxic solvent with a high boiling point, thus making it hard to remove from the reaction mixture. Additionally, it has been proven that hydrolysis of DMF results in the formation of FA, making it difficult for the accurate quantification of the product by the photoreduction of $\mathrm{CO}_{2} \cdot{ }^{39}$ Therefore, Chardon-Noblat et al. searched for new Mn-based photocatalysts in alternative solvents. They proposed Mn tricarbonyl complexes, which contained a 1,10-phenanthroline5,6-dione ligand (Table 3; $\mathrm{Mn}$ (phen-dione)(CO) ${ }_{3} \mathrm{Br}, 38$ and $\mathrm{Mn}$ (phen-dione)(CO) $\left.{ }_{3} \mathrm{MeCN}, 39\right)$. Photocatalytic experiments were performed using a Mn-based photocatalyst $(0.1 \mathrm{mM})$, $\mathrm{Ru}(\mathrm{bpy})_{3} \mathrm{Cl}_{2}$ as the photosensitizer $(0.1 \mathrm{mM})$ and BNAH $(0.1 \mathrm{M})$ as the sacrificial reductant in a $4: 1(\mathrm{v} / \mathrm{v}) \mathrm{MeCN}$ : TEOA solvent mixture (Table 3). Both of these Mn catalysts generated formate as the major reduction product with a $\mathrm{TON}_{\mathrm{FA}}$ of 52 and 48 , respectively. When the solvent mixture was changed to 
Table 3 Homogeneous $\mathrm{Mn}$-based photocatalysts for $\mathrm{CO}_{2}$ to $\mathrm{FA}$ reduction and a $\mathrm{Zn}$-based photosensitizer

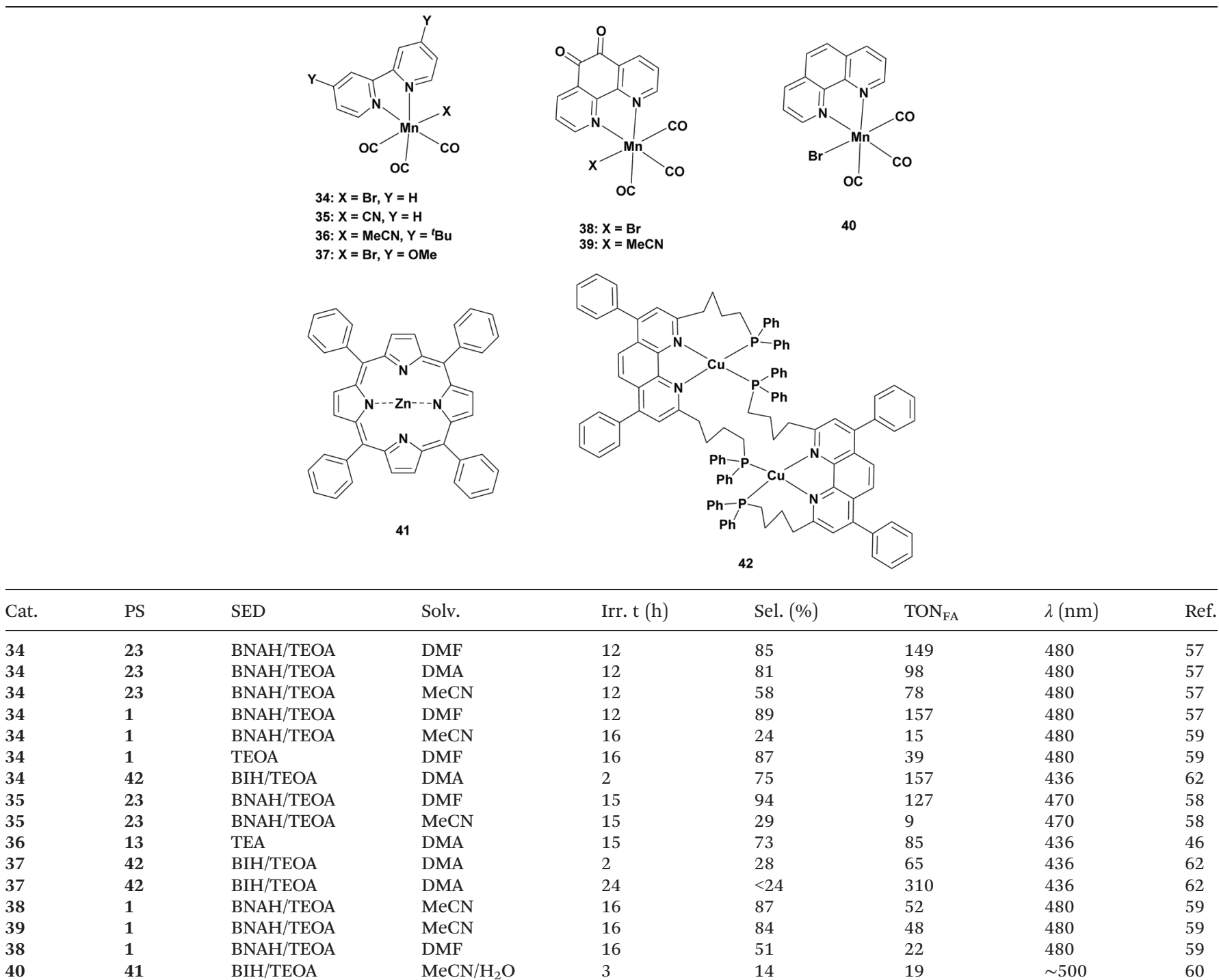

Cat. represents catalyst; PS represents photosensitizer; SED represents sacrificial electron donor; Irr. t represents irradiation time; Sel. represents selectivity; $\mathrm{TON}_{\mathrm{FA}}$ represents turnover number for formic acid generation; $\lambda$ represents wavenumber of incident light; Ref. represents reference. Selectivities and TONs were determined after the corresponding irradiation times unless stated otherwise.

DMF : TEOA, formate generation decreased to a $\mathrm{TON}_{\mathrm{FA}}$ of 22 and the selectivity decreased as well $\left(\mathrm{TON}_{\mathrm{CO}}\right.$ of 21$)$. Additionally, a reference $\mathrm{Mn}$ photocatalyst ([Mn(bpy)(CO) $\left.\left.{ }_{3} \mathrm{Br}\right]\right)$ was examined under these reaction conditions which provided $\mathrm{CO}$ as the major product $\left(\mathrm{TON}_{\mathrm{CO}}\right.$ of $47, \mathrm{TON}_{\mathrm{FA}}$ of 15$)$ in the MeCN : TEOA solvent mixture whereas formate was produced in the DMF : TEOA mixture $\left(\mathrm{TON}_{\mathrm{FA}}\right.$ of 39). Notably, previous photoreductions using Mn-based photocatalysts in MeCN provided $\mathrm{CO}$ as the major reduction product. The difference in selectivity could be explained by in situ UV-VIS studies, which revealed a different intermediate from the usual Mn dimer, although these intermediates were too unstable for further characterization. ${ }^{59}$

As discussed earlier, Ishitani et al. have developed a ringshaped multinuclear $\mathrm{Re}^{\mathrm{I}}$ complex with cis,trans-[Re(bpy)
$\left.(\mathrm{CO})_{2}(\mathrm{P}-\mathrm{P})_{2}\right]$ (Table $\left.1 ; 13\right)$ as the repeating unit, which exhibited excellent photochemical properties. This Re-complex was used as a photosensitizer using fac-[Mn(dtbb) $\left.(\mathrm{CO})_{3}\left(\mathrm{CH}_{3} \mathrm{CN}\right)\right]^{+}$ (Table 3 ; 36) as the photocatalyst in an equimolar ratio in a $\mathrm{CO}_{2}$-saturated DMA : TEOA (5:1 v/v) solvent mixture. Formate was produced as the main reduction product with a $\mathrm{TON}_{\mathrm{FA}}$ of 85 , while $\mathrm{CO}$ was formed as a minor product with a $\mathrm{TON}_{\mathrm{CO}}$ of 32. The addition of a strong sacrificial reductant such as BIH did not improve the reaction yield, which stated that the Re photosensitizer was excellent in exciting the photocatalyst itself. $^{46}$

Ruthenium and to a lesser extent rhenium complexes have been widely used as photosensitizers in the reduction of $\mathrm{CO}_{2}$, since the Mn-based photocatalyst was not able to absorb visible light irradiation itself. Owing to the higher price of 
Ru-based photosensitizers, Bian et al. reported a Mn-based photosensitizer. Their experiments were conducted using fac$\left[\mathrm{Mn}(\right.$ phen $\left.)(\mathrm{CO})_{3} \mathrm{Br}\right]($ Table $3 ; \mathbf{4 0})(0.5 \mathrm{mM})$ as the precursor for the photocatalyst, ZnTPP (Table $3 ; \mathbf{4 1}$ ) as the photosensitizer and TEA as a sacrificial reductant in a $20: 1(\mathrm{v} / \mathrm{v}) \mathrm{MeCN}: \mathrm{H}_{2} \mathrm{O}$ solvent mixture under a $\mathrm{CO}_{2}$ atmosphere. Several photocatalyst to photosensitizer ratios were examined, where a ratio of $4: 1$ provided the highest formation of formate $\left(\mathrm{TON}_{\mathrm{FA}}\right.$ of 19). However, CO was the major reduction product $\left(\mathrm{TON}_{\mathrm{CO}}\right.$ of 119). ${ }^{60}$

Later, Ishitani et al. substituted the precious metal photosensitizer with a copper photosensitizer. Previous studies revealed CuPS complexes as an excellent photosensitizer for the reduction of $\mathrm{CO}_{2} \cdot{ }^{61}$ As a result, Ishitani et al. performed experiments using a Mn-based photocatalyst (0.05 mM), CuPS (Table $3 ; 42)$ as the photosensitizer $(0.25 \mathrm{mM})$ and $\mathrm{BIH}$ $(10 \mathrm{mM})$ as the sacrificial reductant in a $4: 1(\mathrm{v} / \mathrm{v})$ DMA : TEOA solvent mixture under a $\mathrm{CO}_{2}$ atmosphere. In the case of $\mathrm{Mn}$ (bpy) $(\mathrm{CO})_{3} \mathrm{Br}$, formate was the major product with a TON $\mathrm{FA}_{\mathrm{F}}$ of 157. However, CO was also generated $\left(\mathrm{TON}_{\mathrm{CO}}\right.$ of 50$)$. In the case of $\mathrm{Mn}(4-\mathrm{OMe}-\mathrm{bpy})(\mathrm{CO})_{3} \mathrm{Br}$ (Table $\left.3 ; 37\right)$, CO was the main product $\left(\mathrm{TON}_{\mathrm{CO}}\right.$ of 164) and formate was produced to a lesser extent $\left(\mathrm{TON}_{\mathrm{FA}}\right.$ of 65$)$. After 2 hours of irradiation, BIH was completely consumed, and hence the reaction stopped after $2 \mathrm{~h}$. To see the effect of the amount of $\mathrm{BIH}$, the reaction was repeated using $0.1 \mathrm{M}$ of $\mathrm{BIH}$ in the $\mathrm{Mn}(4-\mathrm{OMe}-\mathrm{bpy})(\mathrm{CO})_{3} \mathrm{Br}$ system. After $24 \mathrm{~h}$, the $\mathrm{TON}_{\mathrm{FA}}$ of formate was increased to 310 and simultaneously the $\mathrm{TON}_{\mathrm{FA}}$ of $\mathrm{CO}$ was increased to 1004, which indicated that consumption of BIH stopped the reaction process. Although the reaction using $\mathrm{Mn}(\mathrm{bpy})(\mathrm{CO})_{3} \mathrm{Br}$ was not performed with prolonged irradiation times with a larger amount of $\mathrm{BIH}$, it is safe to say that the $\mathrm{TON}_{\mathrm{FA}}$ would also increase. Furthermore, the increased reaction time showed that CuPS was a very stable and efficient redox photosensitizer for the photoreduction of $\mathrm{CO}_{2}{ }^{62}$

In summary, like the Co-complexes, the main advantage is the use of an Earth-abundant metal instead of a precious metal. A high $\mathrm{TON}_{\mathrm{CO}}$ can be obtained, but the $\mathrm{TON}_{\mathrm{FA}}$ still remains a problem. Additionally, ligand diversity should be thoroughly investigated to achieve high selectivity.

\section{Iron, molybdenum, iridium and rhenium complexes}

Iron complexes. Robert et al. focussed on the replacement of Ru-based catalysts by Earth abundant metals. They observed that a cobalt complex bearing a pentadentate N5 ligand was able to reduce $\mathrm{CO}_{2}$ exclusively to $\mathrm{CO}$ in a high faradaic yield. Pleased by this result, photocatalytic experiments were performed using this catalyst and $\operatorname{Ir}(\mathrm{ppy})_{3}$ (Table $4 ; 44$ ) as a photosensitizer in the presence of TEA as a sacrificial reductant using MeCN as the solvent. Here, CO was very selectively (97\%) formed with a $\mathrm{TON}_{\mathrm{CO}}$ of 270 . When the catalyst was replaced by an iron complex bearing the same pentadentate N5 ligand, $\mathrm{Fe}(\mathrm{DPAOP})(\mathrm{Cl})_{2} \quad($ Table $4 ; \quad 43$, DPAOP $=$ 2,13-dimethyl3,6,9,12,18-pentaazabicyclo[12.3.1]-octadeca-1(18),2,12,14,16pentaene), no $\mathrm{CO}$ was detected. Instead, formate was selectively formed with a TON ${ }_{\mathrm{FA}}$ of 5 after 20 hours of irradiation. ${ }^{63}$
So far, only one Fe-based photocatalyst has been reported and due to the extensive demand for Fe-based catalysis, it is expected that more and more novel complexes will appear. Nonetheless, the use of an Fe metal centre has great prosperity, since FA can be formed with higher selectivity. However, the $\mathrm{TON}_{\mathrm{FA}}$ was very low.

Molybdenum complexes. In nature, $\mathrm{CO}_{2}$ reduction to $\mathrm{FA}$ occurs using formate dehydrogenase as the catalyst. Nature makes use of Mo or W mononuclear centres, where the metal ion is chelated by two identical dithiolene ligands, called molybdopterin (MPT). Therefore, mimicking this biological process is of high interest for the synthesis of FA from $\mathrm{CO}_{2}$. However, the naturally occurring complex has never been isolated, since it decomposes quickly. Additionally, synthesis of these complexes is highly challenging, with the exception of a few dithiolene ligands. In this regard, Fontecave et al. were interested in the development of $\mathrm{Mo} / \mathrm{W}$-dithiolene complexes for the electro- and photoreduction of $\mathrm{CO}_{2}$. In 2018, they reported the use of $\mathrm{Ni}(\mathrm{qpdt})_{2}$ (Table $4 ; 45$ ) (qpdt = quinoxalinepyran-fused dithiolene ligand) as an electrocatalyst for the reduction of $\mathrm{CO}_{2}$ to $\mathrm{FA}$, although it was believed that it did not act as the catalyst since it was unstable in protic mixtures. ${ }^{64}$ This was explained by the major difference between the qpdt and MPT ligands, which is the oxidation state of the central pyrazine ring, where it is fully oxidized in qpdt and fully reduced in MPT. For this reason, two new pqdt derived ligands were reported where the central pyrazine ring was in the twoelectron (H-qpdt) or the four-electron (2H-qpdt) reduced state. With these ligands, two Mo complexes ([Mo(O)(H-qpdt $\left.)_{2}\right]^{2-}$ (Table $4 ; 46)$ and $\left[\mathrm{Mo}(\mathrm{O})(2 \mathrm{H} \text {-qpdt })_{2}\right]^{-}$(Table $\left.4 ; 47\right)$ ) were synthesized and used as photocatalysts in $\mathrm{CO}_{2}$ reductions. For completion, the unreduced $\mathrm{Mo}(\mathrm{O})(\mathrm{qpdt})_{2}$ (Table $4 ; 48$ ) was also used as a photocatalyst. A typical experiment included the Mo-based catalyst and $\left[\mathrm{Ru}(\mathrm{bpy})_{3}\right]^{2+}$ as the photosensitizer in a $1: 10$ ratio. $\mathrm{BIH}$ was added as the sacrificial reductant and a $5: 1(\mathrm{v} / \mathrm{v}) \mathrm{MeCN}$ : TEOA solvent mixture was used. All of these three complexes reduced $\mathrm{CO}_{2}$ to formate with a $\mathrm{TON}_{\mathrm{FA}}$ of 31 , 83 and 80 using $\left(\left[\mathrm{Mo}(\mathrm{O})(\mathrm{H}-\mathrm{qpdt})_{2}\right]^{2-},\left[\mathrm{Mo}(\mathrm{O})(2 \mathrm{H}-\mathrm{qpdt})_{2}\right]^{-}\right.$and $\left[\mathrm{Mo}(\mathrm{O})(\mathrm{qpdt})_{2}\right]^{2-}$ respectively, however all of them also produced an equal or larger amount of $\mathrm{H}_{2} \cdot{ }^{65}$

Iridium complexes. There were already many iridium-based catalysts reported for the photochemical conversion of $\mathrm{CO}_{2}$ to CO. In particular, the $[\operatorname{Ir}(\mathrm{tpy})(\mathrm{ppy}) \mathrm{Cl}]^{+}$(Table $\left.4 ; 49\right)$ (tpy = $2,2^{\prime}: 6^{\prime}, 2^{\prime \prime}$-terpyridine) catalyst was promising since it was able to selectively reduce $\mathrm{CO}_{2}$ to $\mathrm{CO} .{ }^{66}$ Since the $\mathrm{TON}_{\mathrm{FA}}$ was at the lower end (38), Sato et al. performed research for further optimization of this catalyst. They performed photocatalytic experiments using an Ir-based catalyst, where the ppy ligand was replaced by a bpy ligand (Table 4; 50). Remarkably, formate was produced as the major product $\left(\mathrm{TON}_{\mathrm{FA}}\right.$ of 20$)$, where $\mathrm{CO}$ was produced as the minor product $\left(\mathrm{TON}_{\mathrm{CO}}\right.$ of 2$)$. The change in selectivity was explained by measuring the mechanism. Both the ppy and bpy based Ir complexes were changed to the corresponding metal-hydride complex, i.e. $[\operatorname{Ir}(\mathrm{tpy})(\mathrm{ppy}) \mathrm{H}]^{+}$and $[\operatorname{Ir}(\mathrm{tpy})(\mathrm{bpy}) \mathrm{H}]^{2+}$, respectively. However, in the case of $[\operatorname{Ir}(\operatorname{tpy})(\mathrm{bpy}) \mathrm{H}]^{2+}$, further conversion was observed 
Table 4 Homogeneous Fe-, Mo-, Ir- and Re-based photocatalysts for $\mathrm{CO}_{2}$ to FA reduction with their photosensitizers and a Ni-based photocatalyst for $\mathrm{CO}_{2}$ to $\mathrm{CO}$ reduction
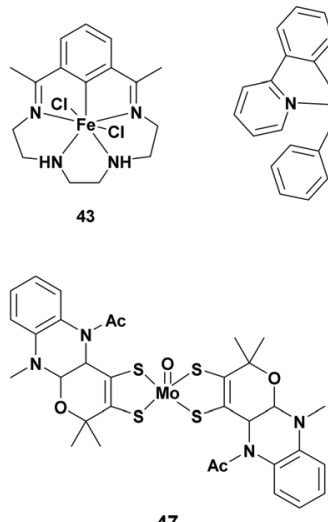

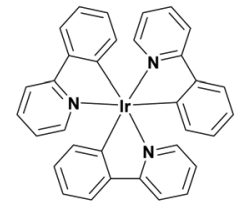

44

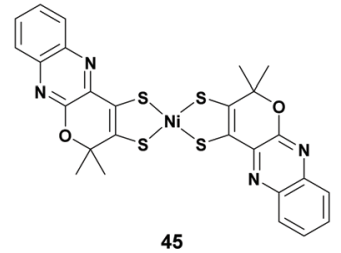

45
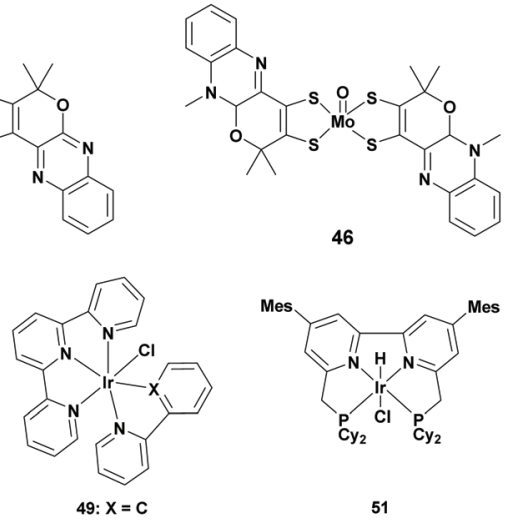

50: $x=C$
$X=N$

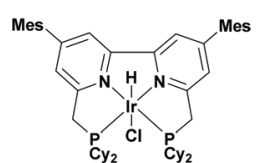

51

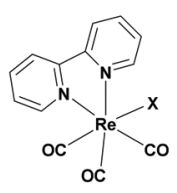

52

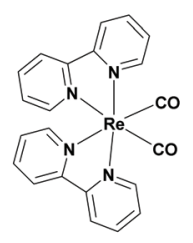

53

\begin{tabular}{|c|c|c|c|c|c|c|c|c|}
\hline Cat. & PS & SED & Solv. & Irr. t (h) & Sel. (\%) & $\mathrm{TON}_{\mathrm{FA}}$ & $\lambda(\mathrm{nm})$ & Ref. \\
\hline 43 & 44 & TEA & MeCN & 20 & $>99$ & 5 & 460 & 63 \\
\hline 46 & 1 & BIH/TEOA & MeCN & 15 & 33 & 31 & 400 & 65 \\
\hline 47 & 1 & BIH/TEOA & MeCN & 15 & 39 & 83 & 400 & 65 \\
\hline 48 & 1 & BIH/TEOA & MeCN & 15 & 10 & 80 & 400 & 65 \\
\hline 50 & N.A. & TEOA & MeCN & 24 & 90 & 20 & $>410$ & 67 \\
\hline 51 & N.A. & $\mathrm{BIH}$ & $\mathrm{DMA} / \mathrm{H}_{2} \mathrm{O}$ & 145 & 87 & 2080 & $>400$ & 69 \\
\hline 53 & N.A. & TEOA & DMA & 24 & $>99$ & 10 & 405 & 71 \\
\hline 53 & 1 & TEOA & DMA & 24 & 88 & 2750 & 405 & 71 \\
\hline
\end{tabular}

Cat. represents catalyst; PS represents photosensitizer; SED represents sacrificial electron donor; Irr. $t$ represents irradiation time; Sel. represents selectivity; $\mathrm{TON}_{\mathrm{FA}}$ represents turnover number for formic acid generation; $\lambda$ represents wavelength of the incoming radiation; Ref. represents reference; N.A. represents not applicable. Selectivities and TONs were determined after the corresponding irradiation times unless stated otherwise.

for an $[\operatorname{Ir}(\mathrm{L}-\mathrm{L})(\mathrm{bpy}) \mathrm{H}]^{2+}$ complex, with L-L, an unknown, unidentified ligand. Therefore, it was believed that the metalhydride acted as the photocatalyst for $\mathrm{CO}$ generation, whereas the further converted complex acted as the photocatalyst for formate generation. Later it was found that the L-L ligand corresponded to the reduced form of tpy, namely piperidine-2,6di-2-pyridine. It is important to note that no additional photosensitizer was used in this reaction and this caused a lower $\mathrm{TON}_{\mathrm{FA}}$ for formate generation. ${ }^{67}$

Most photocatalytic systems made use of both a photosensitizer and a catalyst for the conversion of $\mathrm{CO}_{2}$ to FA. However, using a metal complex which exhibits both of these properties gives the advantage of lowering the activation energy and controlling the selectivity. For this reason, many systems were reported using metal complexes possessing both these properties. However, in most of the cases, CO was formed as the major product. ${ }^{68}$ In 2020 , Saito et al. reported the use of a tetradentate PNNP-type Ir complex Mes-IrPCy 2 (Table $4 ; 51$ ) as a photosensitizer and catalyst for the conversion of $\mathrm{CO}_{2}$ to FA.
The key aspects for designing this catalyst were based on molecular engineering: (i) use of bulky PNNP ligands to prevent catalyst degradation and for controlling the selectivity and (ii) use of bipyridyl ligands with $\mathrm{CH}_{2} \mathrm{P}$ groups, which can act as additional proton donors. The catalyst was examined in a 9:1 (v/v) DMA $: \mathrm{H}_{2} \mathrm{O}$ solution containing $\mathrm{BIH}$ as the sacrificial reductant under a $\mathrm{CO}_{2}$ atmosphere. Formate was selectively $(87 \%)$ produced with a $\mathrm{TON}_{\mathrm{FA}}$ of 2080 , whereas $\mathrm{CO}$ was also generated with a $\mathrm{TON}_{\mathrm{CO}}$ of $470 .{ }^{69}$

In conclusion, Ir-based complexes are highly suitable for the photocatalytic reduction of $\mathrm{CO}_{2}$ to FA. Moreover, reported Ir-based catalytic systems do not require an additional PS since the catalyst itself can adsorb the incident light very efficiently. Here, formate was formed with high selectivity and with a higher $\mathrm{TON}_{\mathrm{FA}}$. Despite these great advantages, the main disadvantage of Ir-based metal complexes is their higher price.

Rhenium complexes. Rhenium complexes have been used for more than 30 years for the photocatalytic reduction of $\mathrm{CO}_{2} \cdot{ }^{70}$ Photocatalytic reductions using $\mathrm{Re}$ complexes were 
selective, where CO was formed as the major reduction product. In particular, the $\operatorname{Re}($ bpy $)(\mathrm{CO})_{3} \mathrm{X}$ (Table 4 ; 52) complexes were studied thoroughly since they functioned as both the photosensitizer and the catalyst. With the objective of finding new photocatalysts possessing both photosensitizing and catalytic properties, Richeson et al. targeted their research on bis(diimine) Re complexes, based on previous Re mono (diimine) and $\mathrm{Ru}$ bis(diimine) species. In the first experiment, $\mathrm{CO}_{2}$ was reduced using $\left[\mathrm{Re}(\mathrm{bpy})_{2}(\mathrm{CO})_{2}\right]$ OTf (Table $4 ; 53$ ) $(4 \mu \mathrm{mol})$ without any addition of a photosensitizer in a $4: 1$ (v/v) DMA : TEOA solvent mixture. Remarkably, almost no CO was detected, whereas formate was selectively formed ( $\mathrm{TON}_{\mathrm{FA}}$ of 10). In the second experiment, $\left[\mathrm{Ru}(\mathrm{bpy})_{3}\right]^{2+}(1 \mathrm{mM})$ was added as a photosensitizer to $0.01 \mathrm{mM}$ of the catalyst in a $4: 1$ (v/v) DMA : TEOA solvent mixture. As expected, the reactivity of the photocatalytic system increased $\left(\mathrm{TON}_{\mathrm{FA}}\right.$ of 2750$)$, where at the same time the selectivity slightly dropped $(88 \%){ }^{71}$

In conclusion, switching from Earth abundant metal catalysts to Ir- and Re-based photocatalysts ensured higher TONs $\left(\mathrm{TON}_{\mathrm{FA}}>2000\right)$. Compared to the Rh-based catalysts, the activity was lower, but the selectivity increased to almost $90 \%$. However, it will be excellent progress if this high selectivity can be achieved by Earth abundant metal complexes.

\section{Metal-free catalysts or photosensitizers}

Homogeneous photoreduction of $\mathrm{CO}_{2}$ is extensively studied using metal complexes. However, photoreduction of $\mathrm{CO}_{2}$ using metal-free photocatalysts has been reported in 1990 by Yanagida et al. Earlier, they reported that $p$-terphenyl (Table 5; 54) was an effective catalyst for the photoreduction of acetaldehyde to ethanol in the presence of TEA as an electron donor, which induced the interest in using $p$-terphenyl as a catalyst for the photoreduction of $\mathrm{CO}_{2} \cdot{ }^{72}$ Although previous reports stated that photochemical reactions using $\mathrm{CO}_{2}$ and hydrocarbons generated the carboxylated hydrocarbon, Yanagida et al. performed research on the photoreduction of $\mathrm{CO}_{2}$ in the presence of $p$-terphenyl. ${ }^{73}$ To their delight, a $\mathrm{CO}_{2}$ saturated DMF:TEA mixture in the presence of $p$-terphenyl was irradiated for 15 hours, which resulted in the formation of formate $\left(\mathrm{TON}_{\mathrm{FA}}\right.$ of 3$)$ and a trace amount of CO. The experiment was repeated with different solvents, where MeCN and THF (tetrahydrofuran) yielded a trace amount of reduction products. It was also found that methanol and ethanol yielded no reduction products. In the second stage, they examined other terphenyls for the photoreduction of $\mathrm{CO}_{2}$. Both $o$-terphenyl (Table $5 ; 55$ ) and $m$-terphenyl (Table $5 ; 56$ ) showed less reactivity compared to $p$-terphenyl. Additionally the insoluble polymer PPP (Table 5; 57, poly ( $p$-phenylene)) was examined, which resulted in the formation of formate with low efficiency. $^{74}$

Based on a report where metal cyclam complexes were used as an electron mediator, Yanagida and co-workers continued their research. ${ }^{75}$ They investigated the photoreduction of $\mathrm{CO}_{2}$ by $p$-terphenyl in the presence of $\mathrm{Co}^{3+}$-cyclam (Table $5 ; 58$ ) or $\mathrm{Ni}^{2+}$-cyclam (Table 5; 59) for investigating the electron mediation properties. It has to be mentioned that methanol had to be added to the mixture in order to solubilize the cyclam complex. They found that no formate was formed in the $\mathrm{DMF} / \mathrm{MeOH}$ solvent mixture when the $\mathrm{Co}^{3+}$-cyclam complex was used, whereas CO was selectively formed. Switching the solvent mixture to $\mathrm{MeCN} / \mathrm{MeOH}$, formate was formed to some extent, whereas $\mathrm{CO}$ remained the major product (1:2 ratio). Unfortunately, the $\mathrm{Ni}^{2+}$-cyclam complex was unable to reduce $\mathrm{CO}_{2}$ photochemically to neither formate nor $\mathrm{CO}$. When the reaction was performed in an $\mathrm{MeCN}: \mathrm{H}_{2} \mathrm{O}$ mixture, formate was formed as the major product, however, the activity of the system was dropped. ${ }^{76}$

Lehn et al. reported that the tertiary amine electron donor influenced the photoreduction of $\mathrm{CO}_{2}$, hence further research was performed by Yanagida and co-workers. ${ }^{77}$ It was found that when $\beta$-hydroxylated tertiary amines, such as TEOA and TIPOA (tri-2-propanolamine) were used, the activity increased more than two fold. Additionally, the structural effects of the 14-membered tetraazamacrocyles (Table $5 ; 60$ to 66) were also examined. Partially unsaturated cyclams with two or four $C$-methyl groups provided comparable activities, whereas more extensively $C$-methylated partially unsaturated cyclams decreased the activity drastically. This was explained by the steric hindrance of the methyl groups which reduced the accessibility of $\mathrm{CO}_{2}$ on the metal centre and also reduced the ligand exchange of the $\mathrm{Cl}$ atom with TEA or TEOA. $\mathrm{CO}_{2}$ reduction was lowered when a completely reduced cyclam was used whereas hydrogen production dominated. This result implied that the absence of $\mathrm{N}-\mathrm{H}$ groups reduced the $\mathrm{CO}_{2}$ binding probability. $\mathrm{N}$-Methylated cyclams did not show any activity in the photoreduction of $\mathrm{CO}_{2}$, which was explained by the steric hindrance for $\mathrm{CO}_{2}$ binding. ${ }^{22}$ Since the results of these photoreductions were comparable or worse, they are not given in the table.

On the other hand, photoreaction systems using phenazine (derivatives) as a photosensitizer were reported. ${ }^{78,79}$ Yanagida et al. continued their research with the use of phenazine (Table $5 ; 67$ ) instead of $p$-terphenyl as a photosensitizer. A typical experiment included the Co-cyclam complex as the catalyst, phenazine as the photosensitizer and TEA as the sacrificial reductant in a $1: 10(\mathrm{v} / \mathrm{v}) \mathrm{MeCN}: \mathrm{MeOH}$ solvent mixture under a $\mathrm{CO}_{2}$ atmosphere. Remarkably, they observed the selective formation of formate with a trace amount of $\mathrm{CO}$ and $\mathrm{H}_{2}$. Phenazine was gradually degraded in the photocatalytic system. GCMS and NMR analyses revealed that 2-ethylphenazine (Table $5 ; 68$ ) was formed, along with other unidentified products. Later, it was found that 2-ethylphenazine was as effective as phenazine for the photoreduction of $\mathrm{CO}_{2}$ to formate. ${ }^{80}$

Previous examples only made use of a metal-free photosensitizer. It took until 2013 before a metal-free catalyst was reported for the photoreduction of $\mathrm{CO}_{2}$ to $\mathrm{FA}$, although the main goal was to obtain methanol. This research was based on the electrocatalytic reduction of $\mathrm{CO}_{2}$ to methanol using a pyridine (Py) catalyst. Only Pt or Pd electrodes were active in the electrocatalytic system, since they shift the reduction potential to more positive values compared to $\mathrm{Hg}$ electrodes. 
Table 5 Homogeneous metal-free photocatalysts or photosensitizers for $\mathrm{CO}_{2}$ to FA reduction with Co-, Mn- and Ru-based photocatalysts<smiles>c1ccc(-c2ccc(C34CCCCC3C4)cc2)cc1</smiles>

54<smiles>CC1=NCCNCC(C)=NCCNCC1</smiles>

61<smiles>c1ccc(-c2ccccc2-c2ccccc2)cc1</smiles>

55<smiles>CC1=NCCCNC(C)C(C)=NCCCN1</smiles>

62<smiles>c1ccc(-c2cccc(-c3ccccc3)c2)cc1</smiles>

56

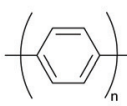

57

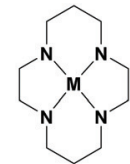

58: $M=$ Co 59: $\mathrm{M}=\mathrm{Ni}$

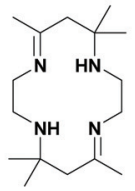

63

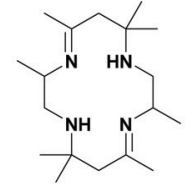

64<smiles>CC1=NCCCN=C(C)C(C)=N1</smiles>

65

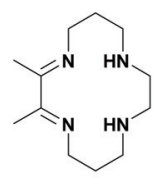

60

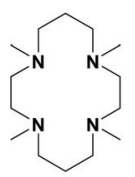

66<smiles>c1ccc2nc3ccccc3nc2c1</smiles>

67

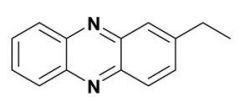

68
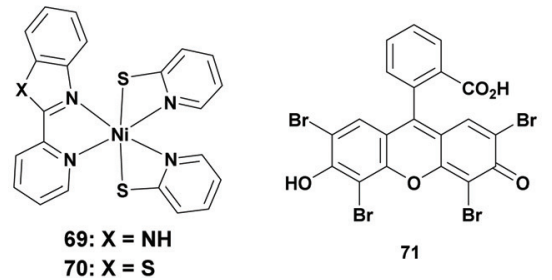

\begin{tabular}{|c|c|c|c|c|c|c|c|c|}
\hline Cat. & PS & SED & Solv. & Irr. t (h) & Sel. (\%) & $\mathrm{TON}_{\mathrm{FA}}$ & $\lambda(\mathrm{nm})$ & Ref. \\
\hline N.A. & 54 & TEA & MeCN & 15 & 95 & 1 & $>290$ & 74 \\
\hline N.A. & 54 & TEA & THF & 15 & 77 & $<1$ & $>290$ & 74 \\
\hline N.A. & 54 & TEA & EtOH & 15 & N.A. & 0 & $>290$ & 74 \\
\hline N.A. & 55 & TEA & DMF & 15 & 79 & $<1$ & $>290$ & 74 \\
\hline N.A. & 56 & TEA & DMF & 15 & 78 & $<1$ & $>290$ & 74 \\
\hline 58 & 54 & TEA & $\mathrm{MeCN} / \mathrm{MeOH}$ & 1 & 30 & 1 & $>290$ & 76 \\
\hline 59 & 54 & TEA & $\mathrm{MeCN} / \mathrm{MeOH}$ & 1 & N.A. & 0 & $>290$ & 76 \\
\hline 58 & 54 & TEA & $\mathrm{MeCN} / \mathrm{H}_{2} \mathrm{O}$ & 1 & 64 & $<1$ & $>290$ & 76 \\
\hline 58 & 54 & TEOA & $\mathrm{MeCN} / \mathrm{MeOH}$ & 1 & 38 & 3 & $>290$ & 22 \\
\hline 58 & 54 & TIPOA & $\mathrm{MeCN} / \mathrm{MeOH}$ & 1 & 21 & $>3$ & $>290$ & 22 \\
\hline 58 & 67 & TEA & $\mathrm{MeCN} / \mathrm{MeOH}$ & 3 & 92 & - & $>290$ & 80 \\
\hline 58 & 68 & TEA & $\mathrm{MeCN} / \mathrm{MeOH}$ & 3 & 94 & - & $>290$ & 80 \\
\hline
\end{tabular}

Cat. represents catalyst; PS represents photosensitizer; SED represents sacrificial electron donor; Irr. t represents irradiation time; Sel. represents selectivity; TON $\mathrm{FA}_{\mathrm{FA}}$ represents turnover number for formic acid generation; $\lambda$ represents wavelength of the incoming radiation; Ref. represents reference; N.A. represents not applicable. Selectivities and TONs were determined after the corresponding irradiation times unless stated otherwise. $-=$ not mentioned. ${ }^{a}$ Phen ligand in stead of bpy ligand. ${ }^{b} \mathrm{KCl}$ was used as an electrolyte.

MacDonnell and co-workers investigated this protocol in terms of photochemistry by replacing the electrodes with a homogeneous photosensitizer and by adding a sacrificial reducing agent. Their photochemical experiments contained pyridine as the photocatalyst, $\left[\mathrm{Ru}(\mathrm{phen})_{3}\right]^{2+}$ as the photosensitizer and ascorbic acid as the sacrificial donor. Although formate was the main product, the system was optimized according to the formation of methanol, since it was the desired product. In a 1 to 1 ratio of cat/PS, formate was produced with a $\mathrm{TON}_{\mathrm{FA}}$ of 11 , whereas methanol was not formed. By decreasing the ratio of cat/PS to $1: 200$, the formation of methanol was increased $\left(\mathrm{TON}_{\mathrm{MeOH}}\right.$ of 0.15$)$, whereas the formation of $\mathrm{HCOOH}$ decreased (Table 5). In electrochemical systems an electrolyte is added and therefore, MacDonnell and co-workers investigated the addition of $\mathrm{KCl}$ to the mixture. This immensely increased the formation of formate to a TON of 76 and doubled the formation of $\mathrm{MeOH}$. Other salts ( $\mathrm{LiCl}, \mathrm{NaCl}, \mathrm{RbCl}$, $\mathrm{CsCl}$ and $\mathrm{MgCl}_{2}$ ) had little to no effect on the system. It is important to mention that the $\mathrm{pH}$ of the mixture had to be 5.0, which implied that both pyridine and the protonated pyridinium salt were important for the catalytic activity. Moreover, in an acidic environment ascorbic acid was protonated which was a less prominent electron donor than the ascorbate molecule. ${ }^{81}$ 
In biological systems, CO dehydrogenase is responsible for the reduction of $\mathrm{CO}_{2}$ to $\mathrm{CO}$. It was reported that the excited state of $\mathrm{CO}$ dehydrogenase possesses an unsaturated $\mathrm{Ni}^{\mathrm{II}}$ species containing three $\mathrm{S}$ ligands. ${ }^{82}$ However, these Nickel thiolate complexes have only been examined for $\mathrm{H}_{2}$ production. ${ }^{83,84}$ In 2020 , Jinheung et al. reported the first use of new mononuclear $\mathrm{N} / \mathrm{S}$ ligated $\mathrm{Ni}^{\mathrm{II}}$ complexes using eosin $\mathrm{Y}$ (71) as the photosensitizer and TEOA as the sacrificial reductant in an EtOH/ $\mathrm{H}_{2} \mathrm{O}$ solvent mixture. Interestingly, complexes $\mathrm{Ni}\left(\right.$ pbi) $(\text { pyS })_{2}$ (Table 5; 69, pbi = 2-(2-pyridyl)-benzimidazole; pyS $=$ pyridine-2-thiolate $)$ and $\mathrm{Ni}(\mathrm{pbt})(\mathrm{pyS})_{2}($ Table $5 ; \mathbf{7 0}, \mathrm{pbt}=$ 2-(2-pyridyl)benzothiazole) photoreduced $\mathrm{CO}_{2}$ to formate in a selective way, with a $\mathrm{TON}_{\mathrm{FA}}$ of 14000 and 13100 , respectively. ${ }^{85}$

In general, the use of organic molecules instead of metalbased compounds increased the sustainability of these reactions. Moreover, organic molecules are often cheaper compared to the transition metal complexes. However, when an organic compound was used as the photocatalyst, a very low $\mathrm{TON}_{\mathrm{FA}}$ was observed. Moreover, UV-light was needed to excite these organocatalysts. Therefore, from the reported values it can be assumed that the organic compounds are not highly efficient at reducing $\mathrm{CO}_{2}$ to FA. On the contrary, when an organic compound was used as a photosensitizer, a very high $\mathrm{TON}_{\mathrm{FA}}$ is reported. Moreover, the use of eosin Y as the photosensitizer yielded FA in a very selective way and visible light can be used. This generated a very interesting avenue for further research to develop novel organic dyes as photosensitizers.

\section{Supramolecular complexes}

Ishitani et al. found in 2005 a new route for the photoreduction of $\mathrm{CO}_{2}$ to $\mathrm{CO}$ using a supramolecular photocatalyst, which possessed both a photosensitizer unit and a photocatalyst unit. The RuRe supramolecular catalysts were already studied for the photoreduction of $\mathrm{CO}_{2}$ to $\mathrm{FA}$ or $\mathrm{CO}{ }^{86-88}$ However, studies using aqueous solutions have not been published. Ishitani et al. stated that the use of water as a solvent and an electron donor would be the ultimate goal, since it is non-toxic and abundantly present on the Earth. Therefore, they continued the research on the photoreduction of $\mathrm{CO}_{2}$ with the use of supramolecular complexes in aqueous solutions. Typically, experiments were carried out using BNAH or BIH. However, these were not water soluble, so other electron donors were also examined and only sodium ascorbate was found to be efficient in this system. Their experiments contained RuReCl (Table 6; 76) as both the photocatalyst and photosensitizer and sodium ascorbate as the sacrificial reductant in water under a $\mathrm{CO}_{2}$ atmosphere. Since RuRe supramolecular complexes form $\mathrm{CO}$ in organic solvents, it was remarkable that formate was produced with a selectivity of $83 \%$ and a $\mathrm{TON}_{\mathrm{FA}}$ of 25 . For comparison, this experiment was repeated with the photocatalyst and photosensitizer mononuclear complexes, which only produced a small amount of formate $\left(\mathrm{TON}_{\mathrm{FA}}\right.$ of 2$)$. The low efficiency of this photocatalytic system was explained by the fast back electron transfer (BET) from the one electron reduced species (OERS) of the photosensitizer unit to the oxidized ascorbate. Furthermore, they investigated the influence on the formation of formate when a mononuclear photosensitizer was added to the mixture. This clearly accelerated the reaction, probably due to the possibility of a new electron supply route to the photocatalyst unit in the RuReCl supramolecular complex. $^{89}$

Ishitani et al. applied the supramolecular complex concept to the $\left[\mathrm{Ru}(\mathrm{bpy})_{3}\right]^{2+}$ (Table $\left.1 ; 1\right)$ photosensitizer and the $\left[\mathrm{Ru}(\mathrm{bpy})_{2}\left(\mathrm{CO}_{2}\right)\right]^{2+}$ (Table $\left.1 ; 5\right)$ catalyst. Compared to mononuclear $\mathrm{Ru}$ complexes, supramolecular complexes required BNAH, since TEOA cannot reduce $\mathrm{CO}_{2}$ under photocatalytic conditions. However, TEOA still played an important role as a base for hydrogen abstraction from the one-electron oxidation product of $\mathrm{BNAH}\left(\mathrm{BNAH}^{-+}\right)$. Additionally, formate was formed under basic conditions, so TEOA basified the mixture for selective formate generation. Firstly, a supramolecular structure containing one unit of both the photosensitizer and catalyst (Table 6; 72) was investigated. Furthermore, they compared the supramolecular system to the system where the photosensitizer and catalyst were separated and concluded that in the case of the supramolecular system more formate was generated (26.9 $\mu \mathrm{mol}$ compared to $5.3 \mu \mathrm{mol}$ ). Moreover, no precipitate was formed using the supramolecular system. Later, they changed the ratio of the photosensitizer to catalyst in the supramolecular system. When more catalyst was present compared to the photosensitizer (Table 6; 73 and 74), the yield of formate was dropped and the $\mathrm{CO}$ yield was increased. For example, a supramolecular structure consisting of one unit of the photosensitizer and three units of the catalyst (Table 6; 74) yielded $5.3 \mu \mathrm{mol}$ of formate and $8.1 \mu \mathrm{mol}$ of CO. In contrast, when more photosensitizer compared to the catalyst was present, the formate yield was increased as seen in the experiment with a supramolecular structure consisting of two units of photosensitizer and one unit of catalyst (Table 6; 75) $\left(30.4 \mu \mathrm{mol}\right.$ and a $\mathrm{TON}_{\mathrm{FA}}$ of 562). In the second stage of the experiment, they tried to improve the reductive quenching of the excited state of the supramolecular system for improved catalyst stability and more efficient formate formation. For this purpose, 1-(4-methoxybenzyl)1,4-dihydronicotinamide (MeO-BNAH) was used as the sacrificial electron donor, where the stability was drastically improved and the formate formation was increased to $36.8 \mu \mathrm{mol}\left(\mathrm{TON}_{\mathrm{FA}}\right.$ of 671$){ }^{90}$

Ishitani et al. were not satisfied with their reported system, since the quantum yield for formate formation was relatively low $\left(\Phi_{\mathrm{HCOOH}}=0.061\right)$. Moreover, studies revealed that BNAH was inefficient in quenching the excited state of the $\mathrm{Ru}$ photosensitizer unit, that a relatively fast BET occurs from the reduced photosensitizer unit to the oxidized $\mathrm{BNAH}^{+}$and that BNA dimers accumulated by deprotonation of $\mathrm{BNAH}^{{ }^{+}}$molecules followed by coupling processes. ${ }^{88,90}$ Therefore, they replaced $\mathrm{BNAH}$ with a benzimidazoline derivative, $\mathrm{BIH}$, which was able to quench the excited state of the photosensitizer unit more efficiently. Furthermore, it was more effective than $\mathrm{BNAH}$ in decreasing the BET. In the first experiment, the $\mathrm{DMF}$ : TEOA solvent mixture containing the $\mathrm{Ru}_{2} \mathrm{Ru}(\mathrm{CO})$ supra- 
Table 6 Homogeneous supramolecular photocatalysts for $\mathrm{CO}_{2}$ to FA reduction
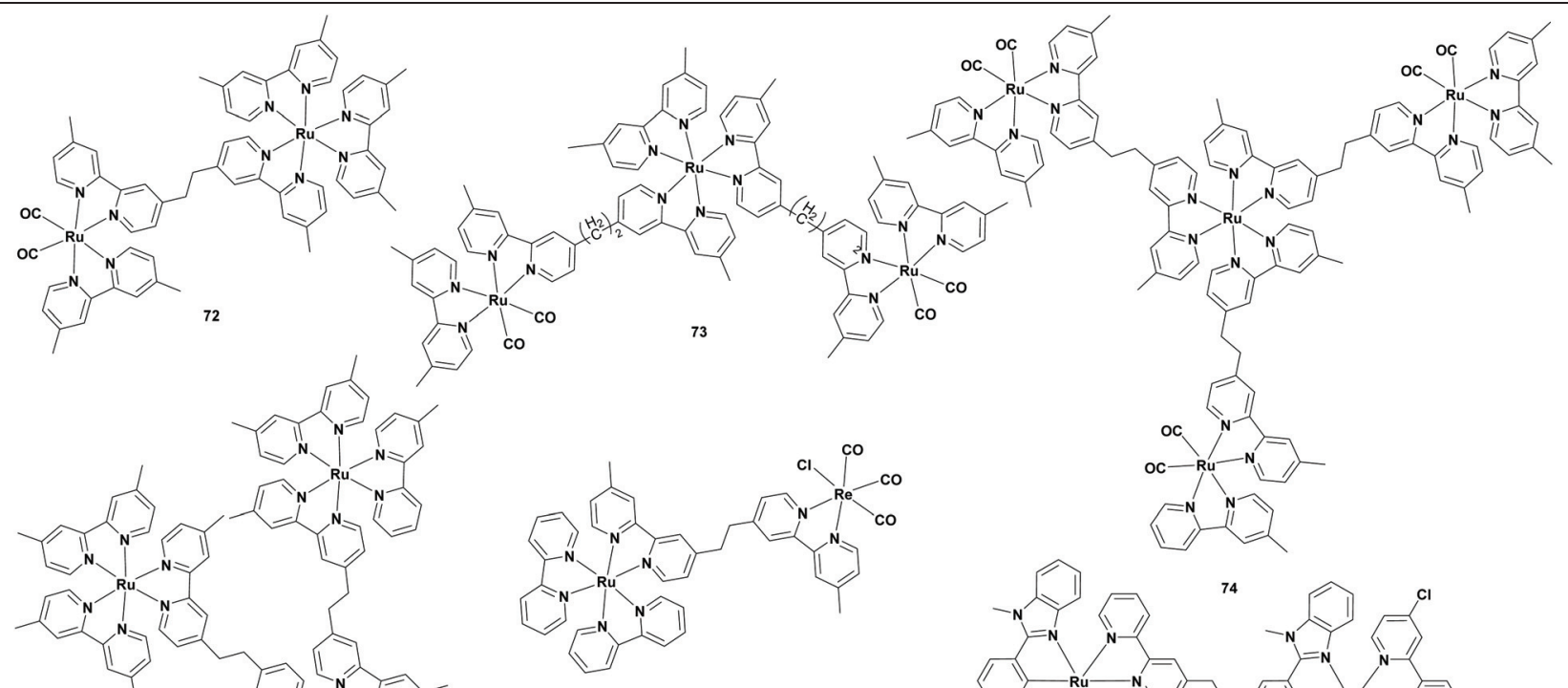

76
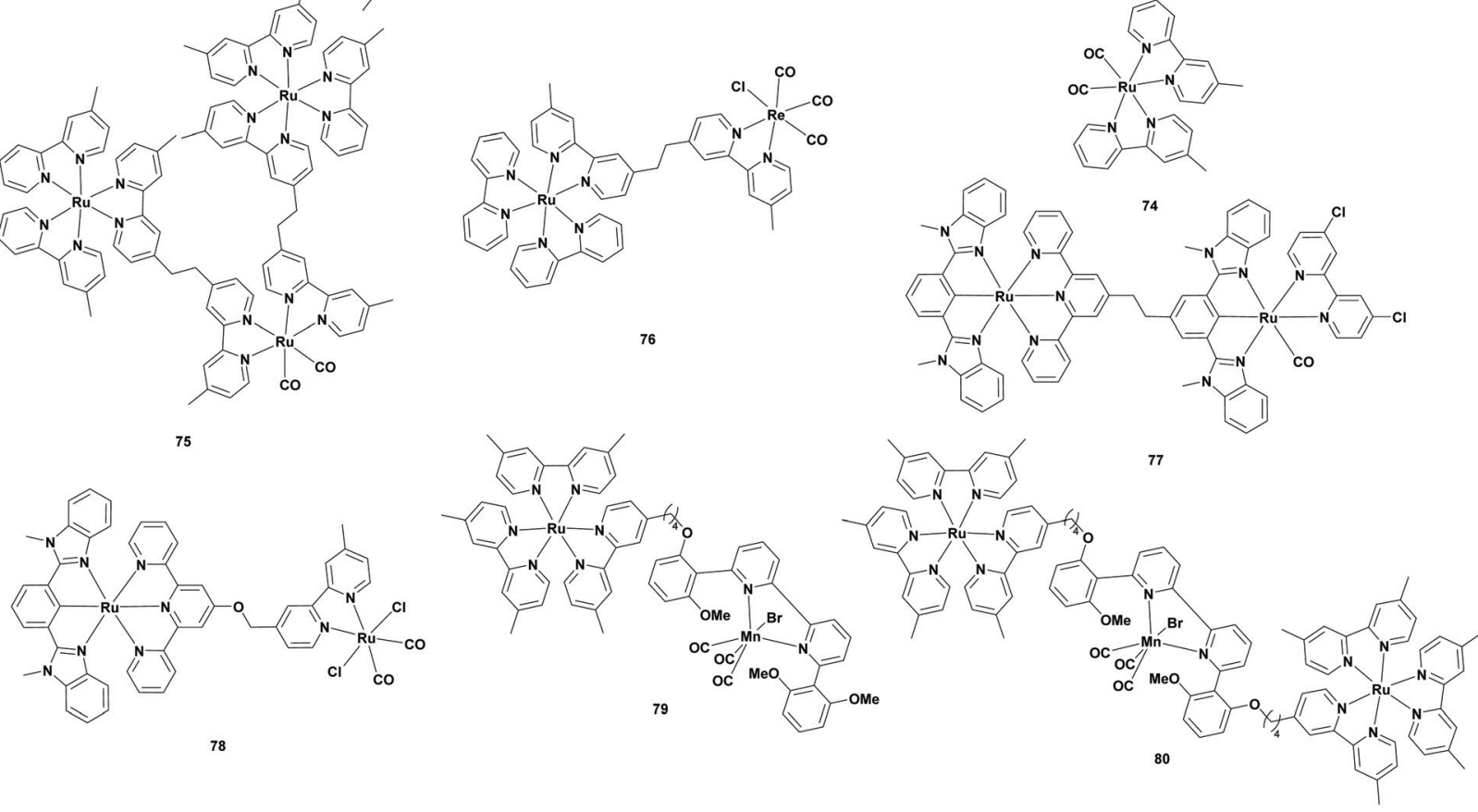

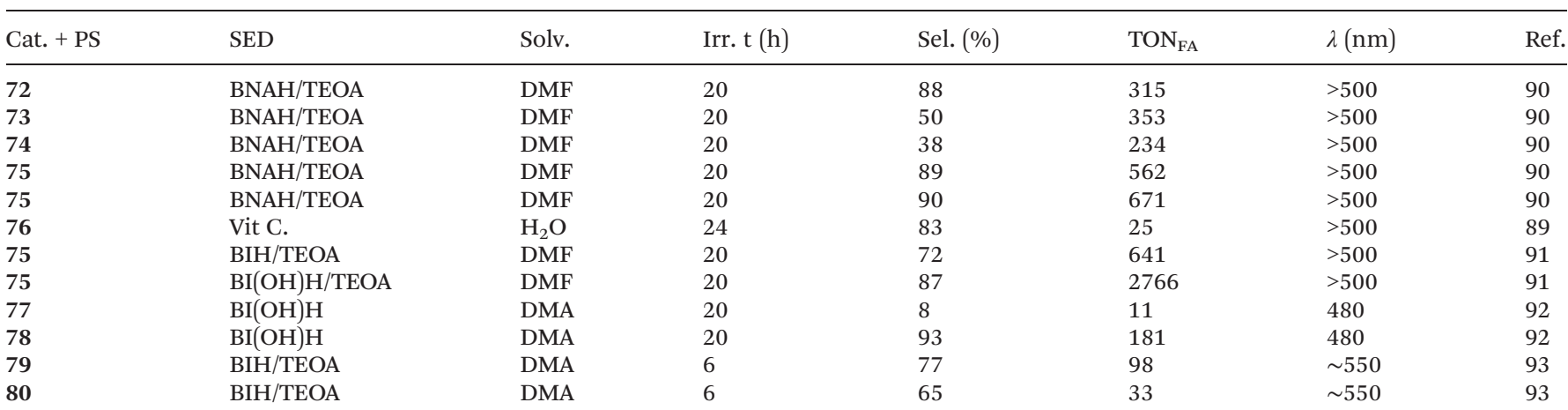

Cat. represents catalyst; PS represents photosensitizer; SED represents sacrificial electron donor; Irr. t represents irradiation time; Sel. represents selectivity; $\mathrm{TON}_{\mathrm{FA}}$ represents turnover number for formic acid generation; $\lambda$ represents wavelength of the incoming radiation; Ref. represents reference; N.A. represents not applicable. Selectivities and TONs were determined after the corresponding irradiation times unless stated otherwise.

molecular complex (Table $6 ; 75$ ) and $\mathrm{BIH}$ as the sacrificial reducing agent was irradiated under a $\mathrm{CO}_{2}$ atmosphere. Here, both the formate and $\mathrm{CO}$ were produced with a $\mathrm{TON}_{\mathrm{FA}}$ of 641 and a TON $\mathrm{CO}$ of 237 , respectively. It should be noted that by switching BNAH to BIH, the TON $\mathrm{FA}_{\mathrm{FA}}$ and the $\Phi_{\mathrm{HCOOH}}$ increased, whereas the selectivity dropped. In the second stage, Ishitani et al. replaced BIH with another benzimidazoline derivative
$\mathrm{BI}(\mathrm{OH}) \mathrm{H}$, since this compound was able to supply two electrons and two protons to eliminate the proton shortage in the reaction mixture. Using $\mathrm{BI}(\mathrm{OH}) \mathrm{H}$ instead of $\mathrm{BIH}$ under the same conditions, formate was produced with higher efficiency $\left(\mathrm{TON}_{\mathrm{FA}}\right.$ of 2766$)$ and selectivity $(87 \%) .{ }^{91}$

Due to the hybridization of supramolecular complexes to semiconducting heterogeneous materials, Ishitani and co- 
workers developed a new type of supramolecular complex, consisting of a Ru catalyst unit and a Ru photosensitizer unit with two different tridentate ligands. In their first experiment, a DMA : $\mathrm{H}_{2} \mathrm{O}$ solution containing $\mathrm{RuRu}(\mathrm{Cl})(\mathrm{bpy})(\mathrm{CO})$ (Table 6; 77) as the supramolecular complex and $\mathrm{BI}(\mathrm{OH}) \mathrm{H}$ as the sacrificial reductant was irradiated under a $\mathrm{CO}_{2}$ atmosphere. In this case, $\mathrm{CO}$ was formed as the main product $\left(\mathrm{TON}_{\mathrm{CO}}\right.$ of 134$)$ with a minor amount of $\mathrm{FA}\left(\mathrm{TON}_{\mathrm{FA}}\right.$ of 11). In contrast, when $\mathrm{RuRu}(\mathrm{CO})_{2} \mathrm{Cl}_{2}$ (Table 6; 78) was used as the supramolecular complex under the same conditions, FA was the main product $\left(\mathrm{TON}_{\mathrm{FA}}\right.$ of 181). It is noteworthy that the water was the proton source instead of TEOA, which could be the possible reason for the lower TONs. ${ }^{92}$

With the intention of replacing the precious $\mathrm{Ru}$ catalyst unit of the supramolecular complex, Ishitani et al. investigated the use of a $\mathrm{Mn}$ catalyst unit for supramolecular $\mathrm{CO}_{2}$ reduction. This proposal was supported by the Earth abundant Mn, its catalytic behaviour (see the Manganese section) and the fact that mononuclear Mn photocatalysts formed dimers, which decomposed under visible light irradiation. The incorporation of a photosensitizer should suppress the dimerization. In the first reaction, a DMA : TEOA solvent mixture containing the Ru-Mn supramolecular complex (Table 6; 79) and $\mathrm{BIH}$ as a sacrificial reductant was irradiated under a $\mathrm{CO}_{2}$ atmosphere. Here, formate was produced as the major product $\left(\mathrm{TON}_{\mathrm{FA}}\right.$ of 98$)$ and $\mathrm{CO}$ as the minor product $\left(\mathrm{TON}_{\mathrm{CO}}\right.$ of 29$)$. When the mononuclear complexes were added instead of the supramolecular complex, the production rate of formate slowed down. When the $\mathrm{Ru}_{2}-\mathrm{Mn}$ (Table 6; 80) supramolecular complex was used, the formate formation slowed down even further $\left(\mathrm{TON}_{\mathrm{FA}}\right.$ of 33$){ }^{93}$

It can be concluded that the supramolecular complexes are viable alternatives for the photoreduction of $\mathrm{CO}_{2}$ to FA. One of the main advantages is that these complexes possess a PS and the active catalytic centre in the same molecule and for that reason, a straightforward electron transfer occurs from the PS unit to the PC unit. However, synthesis of these complexes is quite challenging and tedious.

\section{Partially homogeneous $\mathrm{CO}_{2}$ photoreduction}

\section{Metal-based semiconductors}

From an economic point of view, heterogenization of the homogeneous catalyst is interesting, since the catalyst can easily be recovered from the reaction mixture and can be recycled. Furthermore, semiconductor-based heterogeneous photocatalysts possess superior oxidation ability. It wasn't until 2010 that Sato et al. linked a Ru complex to a semiconductor for the selective reduction of $\mathrm{CO}_{2}$ to FA. In this combination, the semiconductor was photoexcited, which induced electron transfer from its conduction band to the catalyst in a Z-scheme system. However, the system was not solely photocatalytic since an electric current was required. They chose
$\left[\mathrm{Ru}(\mathrm{bpy})_{2}(\mathrm{CO})_{2}\right]^{2+} \quad($ Table $1 ; \quad 5), \quad\left[\mathrm{Ru}(\mathrm{dcbpy})(\mathrm{bpy})(\mathrm{CO})_{2}\right]^{2+}$ (Table $7 ; 82)$ and $\left[\mathrm{Ru}(\mathrm{dcbpy})_{2}(\mathrm{CO})_{2}\right]^{2+}$ (Table 7; 81) $($ dcbpy $=$ $4,4^{\prime}$-dicarboxy-2,2'-bipyridine) as the catalysts and $\mathrm{N}$-doped $\mathrm{Ta}_{2} \mathrm{O}_{5}$ as the semiconductor-based photocatalyst. The $[\mathrm{Ru}-$

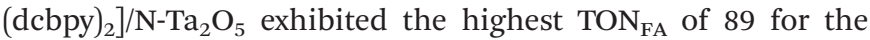
formation of FA per metal complex with more than $75 \%$ selectivity. It was observed that the amount of FA formation was increased linearly upon increasing the amount of the photocatalyst. Using [Ru-(dcbpy)(bpy)CO]/N-Ta $\mathrm{O}_{5}$, the $\mathrm{TON}_{\mathrm{FA}}$ decreased to around 30, whereas using a non-linked catalyst and semiconductor mixture, the $\mathrm{TON}_{\mathrm{FA}}$ decreased to less than 10. It was shown that the carboxylic acid group improved the electron transfer from the semiconductor to the catalyst by direct linkage, however, the exact reason was not clear. ${ }^{94}$

One year later, Suzuki et al. started to find better anchoring groups to enhance the electron transfer, which should exhibit better photoredox activity. Hybrid catalysts with these anchoring groups were typically synthesized by the adsorption of metal complexes onto a semiconductor. In the quest for optimal anchoring groups, each of the metal complexes was synthesized individually. However, with the polar anchoring groups, purification problems of the hybrid material started to arise. To solve this, they reported an alternative approach via direct assembly of the metal complex with ligand-functionalized semiconductors. Here, the phosphonate group was observed to improve the photocatalytic ability of the hybrid catalyst. With the catalyst bearing this anchoring group (Table 7; 83), FA was formed with a $\mathrm{TON}_{\mathrm{FA}}$ of 118 , but CO was also produced with a TON $\mathrm{CO}$ of $67 . .^{95}$

In 2011, Sato et al. transferred their protocol to an aqueous solution, so that carbon-based fuels could be produced from $\mathrm{CO}_{2}$ and $\mathrm{H}_{2} \mathrm{O}$. Since the previously reported [Ru-(dcbpy $\left.)_{2}\right] /$ $\mathrm{N}-\mathrm{Ta}_{2} \mathrm{O}_{5}$ could not maintain its linkage in aqueous solutions, they selected a wide range of different photocatalysts and/or semiconductors such as $\mathrm{N}-\mathrm{Ta}_{2} \mathrm{O}_{5}$, gallium phosphide (GaP) and indium phosphide (InP). Among these hybrid catalysts, the ruthenium-based complexes linked to InP yielded the highest quantity of formate, with in particular the Ru-(dppc) (bpy) complex (Table 7; 84, dppc $=4,4$ '-di(1H-pyrrolyl-3-propyl carbonate)) being linked to InP. When a hybrid catalyst was made using two different Ru-complexes (Table 7; 84 and Ru-(dpe)(bpy), 85, dpe = 4,4'-diphosphate ethyl-2,2'-bipyridine) linked to InP, the FA formation increased even more. This was explained by the dpe ligand which acted as an anchor to form a tight linkage with the surface of InP to accelerate the electron transfer. Later, the reactivity of the hybrid catalyst was determined in the presence of electrolyte solutions such as $\mathrm{NaHCO}_{3}, \mathrm{Na}_{3} \mathrm{PO}_{4}$ and $\mathrm{Na}_{2} \mathrm{SO}_{4}$, since it could increase the photocurrent due to its higher electrical conductivity compared to water. In all of these electrolytes, the production of FA increased, parallel to the drastic increase of the production of hydrogen gas. ${ }^{20}$

Most of the semiconducting material-based photocatalysts produce a tremendous amount of hydrogen gas as the byproduct. Therefore, to gain better selectivity towards the formation of FA, the search for new heterogenized photocatalysts 
Table 7 Homogeneous metal-based photocatalysts for $\mathrm{CO}_{2}$ to FA reduction linked to a metal-based semiconductor

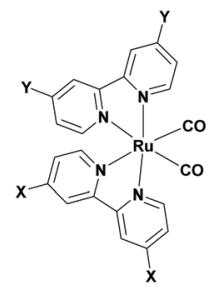

81: $X=Y=\mathrm{COOH}$ 82: $X=H, Y=C O O H$
813: $X=H, Y=P O(O H)$
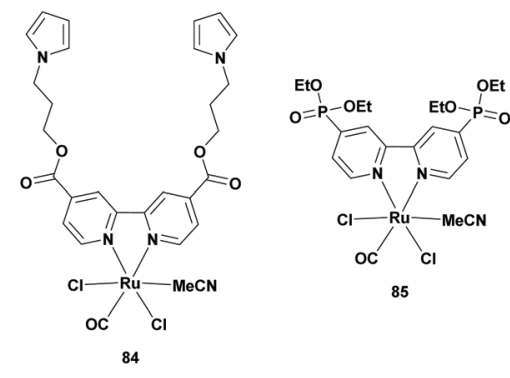

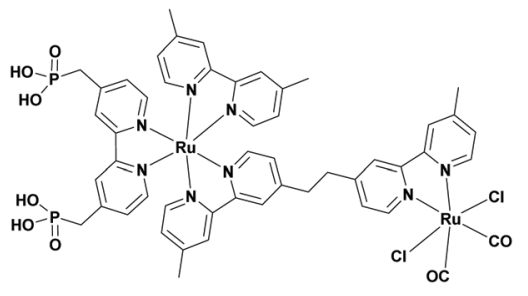

86

\begin{tabular}{|c|c|c|c|c|c|c|c|}
\hline Cat. & $\mathrm{SC}$ & Solv. & Irr. $\mathrm{t}(\mathrm{h})$ & Sel. (\%) & $\mathrm{TON}_{\mathrm{FA}}$ & $\lambda(\mathrm{nm})$ & Ref. \\
\hline 81 & $\mathrm{~N}-\mathrm{Ta}_{2} \mathrm{O}_{5}{ }^{a}$ & $\mathrm{MeCN}^{c}$ & 8 & $>75$ & 89 & $>410$ & 94 \\
\hline 82 & $\mathrm{~N}-\mathrm{Ta}_{2} \mathrm{O}_{5}{ }^{a}$ & $\mathrm{MeCN}^{c}$ & 8 & $>75$ & $>30$ & $>410$ & 94 \\
\hline 83 & $\mathrm{~N}-\mathrm{Ta}_{2} \mathrm{O}_{5}{ }^{a}$ & $\mathrm{MeCN}^{c}$ & 60 & $<50$ & 118 & $>410$ & 95 \\
\hline 84 & $\operatorname{In} \mathrm{P}^{a}$ & $\mathrm{H}_{2} \mathrm{O}$ & N.G. & - & - & $>400$ & 20 \\
\hline $84+85$ & $\operatorname{InP}^{a}$ & $\mathrm{H}_{2} \mathrm{O}$ & N.G. & - & - & $>400$ & 20 \\
\hline $84+85$ & $\operatorname{InP}^{a}$ & $\mathrm{NaHCO}_{3}{ }^{d}$ & N.G. & - & - & $>400$ & 20 \\
\hline $84+85$ & $\operatorname{In} \mathrm{P}^{b}$ & $\mathrm{NaHCO}_{3}{ }^{d}$ & N.G. & - & $18^{e}$ & $>400$ & 97 \\
\hline $84+85$ & $\operatorname{In} \mathrm{P}^{b}$ & $\mathrm{NaHCO}_{3}{ }^{d}$ & N.G. & - & $<12^{f}$ & $>400$ & 97 \\
\hline 86 & $\mathrm{TaON}$ & $\mathrm{MeOH}$ & 9 & 70 & 41 & $>400$ & 21 \\
\hline 86 & $\mathrm{CaTaO}_{2} \mathrm{~N}$ & $\mathrm{DMA}^{c}$ & 15 & $>99$ & 9 & $>400$ & 98 \\
\hline 86 & $\mathrm{Ag}-\mathrm{CaTaO}_{2} \mathrm{~N}$ & $\mathrm{DMA}^{c}$ & 15 & $>99$ & 32 & $>400$ & 98 \\
\hline 86 & $\mathrm{~Pb}_{2} \mathrm{Ti}_{2} \mathrm{O}_{5.4} \mathrm{~F}_{1.2}$ & $\mathrm{MeCN}^{c}$ & 15 & $>99$ & 26 & $>480$ & 102 \\
\hline 86 & $\mathrm{GaN}: \mathrm{ZnO}$ & $\mathrm{Na}_{2} \mathrm{CO}_{3}{ }^{d}$ & 15 & 78 & 359 & 365 & 101 \\
\hline 86 & $\mathrm{TiO}_{2}: \mathrm{Ta} / \mathrm{N}$ & $\mathrm{Na}_{2} \mathrm{CO}_{3}{ }^{d}$ & 15 & 67 & 18 & 365 & 101 \\
\hline 86 & $\mathrm{Li}_{2} \mathrm{LaTa}_{2} \mathrm{O}_{6} \mathrm{~N}$ & $\mathrm{MeCN}^{c}$ & 15 & 97 & 50 & $>400$ & 103 \\
\hline 86 & $\mathrm{Ag}-\mathrm{Li}_{2} \mathrm{LaTa}_{2} \mathrm{O}_{6} \mathrm{~N}$ & $\mathrm{MeCN}^{c}$ & 15 & 99 & 110 & $>400$ & 103 \\
\hline 86 & $\mathrm{Y}_{2} \mathrm{Ta}_{2} \mathrm{O}_{5} \mathrm{~N}_{2}$ & $\mathrm{DMA}^{c}$ & 24 & $>99$ & 5 & $>400$ & 100 \\
\hline 86 & $\mathrm{Ag}-\mathrm{Y}_{2} \mathrm{Ta}_{2} \mathrm{O}_{5} \mathrm{~N}_{2}$ & $\mathrm{DMA}^{c}$ & 24 & $>99$ & 18 & $>400$ & 100 \\
\hline 86 & $\mathrm{Ta}_{3} \mathrm{~N}_{5}$ & $\mathrm{MeCN}^{c}$ & 15 & 93 & - & $>480$ & 107 \\
\hline 86 & $\mathrm{Ag}-\mathrm{Ta}_{3} \mathrm{~N}_{5}$ & $\mathrm{MeCN}^{c}$ & 15 & 98 & - & $>480$ & 107 \\
\hline 86 & $\mathrm{TbTaO}_{x} \mathrm{~N}_{y}$ & $\mathrm{MeCN}^{c}$ & 15 & $>99$ & 19 & $>400$ & 106 \\
\hline
\end{tabular}

Cat. represents catalyst; SC represents semiconductor; Solv. represents solvent; Irr. t represents irradiation time; Sel. represents selectivity; TON FA represents turnover number for formic acid generation; $\lambda$ represents wavelength of the incoming radiation; Ref. represents reference; N.A. represents not applicable. Selectivities and TONs were determined after the corresponding irradiation times unless stated otherwise. $-=$ not mentioned. ${ }^{a} \mathrm{TiO}_{2}$ photoanode was used. ${ }^{b} \mathrm{SrTiO}_{3}$ photoanode was used. ${ }^{c} \mathrm{TEOA}$ as sacrificial electron donor was used. ${ }^{d}$ Aqueous solution. ${ }^{e}$ Two-cell configuration. ${ }^{f}$ One-cell configuration.

was continued. Moreover, the photoreduction of $\mathrm{CO}_{2}$ to FA in the presence of a hybrid catalyst was very complex and was performed in a two-compartment cell, which was divided by a proton exchange membrane, since the produced FA could be re-oxidized by the anode current. Furthermore, these photocatalysts could not oxidize water themselves to utilize it as an electron donor. For this reason, $\mathrm{TiO}_{2}$ was often used as a photocathode. In 2013, Arai et al. proposed the use of a $\mathrm{SrTiO}_{3}$ photoanode since it had a similar bandgap and had already been reported for the oxidation of water. ${ }^{96}$ The catalyst was a RuCP polymer linked to a zinc-doped indium phosphide (Zn-InP) semiconductor (Table 7). Using this catalyst in a two-cell set-up, formate was formed with a $\mathrm{TON}_{\mathrm{FA}}$ of 20 . For comparison, they performed the reaction with $\mathrm{TiO}_{2}$ as the photoanode and found that the formation of formate was less than a fourth compared to when the $\mathrm{SrTiO}_{3}$ photoanode was used. In addition, Arai et al. established a one-cell reactor, where the formation of formate dropped by more than $30 \%$. The increase in formate formation using $\mathrm{SrTiO}_{3}$ was explained by its more negative energy of the conduction band minimum $\left(E_{\mathrm{CBM}}\right)$, which enhanced electron transfer from the photoanode to the photocathode. ${ }^{97}$

Later in 2013, Ishitani et al. reported the first hybrid photocatalyst which was able to reduce $\mathrm{CO}_{2}$ and oxidize methanol at the same time. They chose methanol as the electron donor, since it formed formaldehyde, a widely known bulk chemical. As the heterogeneous unit, they chose a supramolecular complex consisting of $\left[\mathrm{Ru}(\mathrm{dmb})_{2}(\mathrm{MPA}-\mathrm{dmb})\right]^{2+}(\mathrm{MPA}=$ methylene phosphonic acid) as the photosensitizer unit and $\left[\mathrm{Ru}\left(\mathrm{CH}_{2}-\right.\right.$ $\left.\mathrm{dmb})(\mathrm{CO})_{2} \mathrm{Cl}_{2}\right]$ as the catalyst unit (Table 7; 86, RuRu'), whereas tantalum oxynitride ( $\mathrm{TaON}$ ) with $1 \mathrm{wt} \%$ metallic $\mathrm{Ag}$ was chosen as the semiconductor. Using this hybrid structure in methanol, formaldehyde was produced to a great extent with $\mathrm{FA}$ as the main reduction product from $\mathrm{CO}_{2}\left(\mathrm{TON}_{\mathrm{FA}}\right.$ of 41$).^{21}$

It should be noted that hybrid systems for the reduction of $\mathrm{CO}_{2}$ to FA never exceeded the selectivity of more than $80 \%$. Therefore, new hybrid systems were desirable for improving selectivity. The photocatalytic activity of the Z-scheme was highly dependent on the potential of the conduction band of 
the semiconductor, since electron transfer from the semiconductor to the photosensitizer unit plays a crucial role. Therefore, Ishitani et al. continued their research by investigating perovskites as new semiconductors. Using $\mathrm{CaTaO}_{2} \mathrm{~N}$ as the perovskite semiconductor with $\mathrm{RuRu}^{\prime}$ (Table 7; 86) as the catalyst, FA was produced with high selectivity (>99\%) with a $\mathrm{TON}_{\mathrm{FA}}$ of 9. When $\mathrm{Ag}(1 \mathrm{wt} \%)$ was loaded on the semiconductor, the $\mathrm{TON}_{\mathrm{FA}}$ was increased to 32 with the same selectivity. The deposited Ag was explained to trap electrons to mediate charge transfer from the semiconductor to the photosensitizer unit of the RuRu' complex. ${ }^{98}$ Additionally, based on the report of $\mathrm{Li}$ et al., Ishitani et al. also investigated an yttrium-tantalum oxynitride (YTON) as a semiconductor since it was proven to possess photocatalytic activity. ${ }^{99}$ However, when the YTON semiconductor was linked to the RuRu' catalyst to reduce $\mathrm{CO}_{2}$, a lower TON $\mathrm{FA}_{\text {a }}$ of was achieved but with similar selectivity. ${ }^{100}$

Although improvements were made for the catalytic activity and selectivity of the hybrid catalysts for the $\mathrm{CO}_{2}$ reduction to FA, these systems required strong sacrificial reductants. The main goal of using semiconductors was the use of weak reductants such as water. Therefore, Ishitani et al. further investigated the photocatalytic reactivity of $\mathrm{GaN}: \mathrm{ZnO}$, a metal oxynitride solid solution between $\mathrm{GaN}$ and $\mathrm{ZnO}$, and $\mathrm{TiO}_{2}: \mathrm{Ta} / \mathrm{N}$, rutile titania dioxide co-doped with tantalum and nitrogen, since they are well known to oxidize water. In this way, investigation of interfacial electron transfer could be done, since they possessed different conduction band potentials. The photocatalytic activities of both of the semiconductors were investigated when RuRu' was linked to it (Table 7). Both of them provided $\mathrm{FA}$ as the main product, where $\mathrm{TiO}_{2}: \mathrm{Ta} / \mathrm{N}$ had lower activity compared to $\mathrm{GaN}: \mathrm{ZnO}$ due to the inefficient light absorption and this observation was explained by the energy of the conduction band. Back electron transfer from the photosensitizing unit of the RuRu' to the semiconductor was suppressed when the conduction band was elevated in energy. GaN : ZnO possesses a conduction band with negative potential, which exhibited higher reactivity for the photoreduction of $\mathrm{CO}_{2} \cdot{ }^{101}$ This research triggered the interest for the use of mixed anions such as oxyfluorides, oxynitrides and oxysulfides in the photocatalysis discipline, since their valence band can be adjusted to a more negative potential by band-tuning. For this reason, Ishitani et al. developed the oxyfluoride $\mathrm{Pb}_{2} \mathrm{Ti}_{2} \mathrm{O}_{5.4} \mathrm{~F}_{1.2}$ as a semiconductor (Table 7). Normally, photocatalysis using oxyfluorides is unsuitable given the highest electronegativity of fluorine, which is located at the lower part of the valence band. This oxyfluoride photocatalyst was mainly developed for the evolution of $\mathrm{H}_{2}$ but with modification via the linkage with RuRu', it is also capable to reduce $\mathrm{CO}_{2}$ to formate with high selectivity (99\%) and a TON $\mathrm{FA}_{\mathrm{FA}}$ of $26 .{ }^{102}$ In terms of oxynitrides, it was already proven that these semiconductors were able to reduce $\mathrm{CO}_{2}$ to $\mathrm{FA}$ when $\mathrm{RuRu}^{\prime}$ was present. ${ }^{98}$ However, Ishitani et al. proposed that 2D layered oxynitrides may improve the catalytic reactivity compared to $3 \mathrm{D}$ layered oxynitrides (e.g. $\left.\mathrm{CaTaO}_{2} \mathrm{~N}\right)$. Therefore, they synthesized a $2 \mathrm{D}$ layered $\mathrm{Li}_{2} \mathrm{LaTa}_{2} \mathrm{O}_{6} \mathrm{~N}$ perovskite and investigated its photo- catalytic activity by forming a linkage with the RuRu' supramolecular complex (Table 7). FA was produced with a selectivity of $97 \%$ with a $\mathrm{TON}_{\mathrm{FA}}>50$. This experiment was repeated using $\mathrm{Ag}$-deposited $\mathrm{Li}_{2} \mathrm{LaTa}_{2} \mathrm{O}_{6} \mathrm{~N}$ and the reactivity was increased by a factor of two $\left(\mathrm{TON}_{\mathrm{FA}}\right.$ of 110$)$ while maintaining high selectivity (99\%). ${ }^{103}$ The use of oxysulfides for $\mathrm{CO}_{2}$ reduction started with the use of rare-earth-based semiconductors as photocatalysts for water splitting. ${ }^{104}$ It was also reported that rareearth species were effective modifiers for the reduction of $\mathrm{CO}_{2}$ over $\mathrm{Ag} / \mathrm{Ga}_{2} \mathrm{O}_{3}{ }^{105}$ This triggered the interest of Ishitani et al. to use rare-earth metal-based semiconductors $\left(\operatorname{LnTaO}_{x} \mathrm{~N}_{y}\right.$, where $\mathrm{Ln}=$ rare-earth metal) in a Z-scheme fashion for $\mathrm{CO}_{2}$ reduction. Several $\operatorname{LnTaO}_{x} \mathrm{~N}_{y}$ based semiconductors were linked to $\mathrm{RuRu}^{\prime}$ for investigation and the catalytic activity was found to be strongly dependent on the Ln element (Table 7). When Ln represented Nd or Sm, no FA was found, whereas FA was observed when Ln was represented by Gd, Tb, Dy or Ho. Among these, Tb provided the highest reactivity with a selectivity of $>99 \%$. The low reactivity of $\mathrm{Nd}$ and $\mathrm{Sm}$ was explained by their low crystallinity, which enhanced electron-hole recombination processes. ${ }^{106}$

In general, most of the semiconductors absorb wavelengths shorter than $500 \mathrm{~nm}$. Synthesizing semiconductors which absorb at longer wavelengths is important to expand the use of a broader range of the visible spectrum. In 2018, Ishitani et al. reported the use of a $\mathrm{Ta}_{3} \mathrm{~N}_{5}$ semiconductor for the photoreduction of $\mathrm{CO}_{2}$ when it was linked to RuRu' (Table 7). FA was produced in high selectivity (93\%) at a wavelength of $>480 \mathrm{~nm}$, although with lower activity. The activity was increased further using Ag-doped $\mathrm{Ta}_{3} \mathrm{~N}_{5}$ linked to RuRu', while at the same time the selectivity was increased to $98 \% .^{107}$

In conclusion, these heterogenized catalysts possess excellent selectivity for the photoreduction of $\mathrm{CO}_{2}$ to formic acid. However, the use of heterogeneous catalysts decreases the contact surface of $\mathrm{CO}_{2}$ and the active catalytic centre, which translated to a decrease in the efficiency of this catalytic cycle. This method has more potential, since only a few homogeneous catalysts have been anchored onto solid semi-conductor supports. Specifically, when the semi-conductor is doped with Ag-particles, reports have proven that the efficiency can be enhanced tremendously.

\section{$\mathrm{C}_{3} \mathrm{~N}_{4}$ as a metal-free semiconductor}

The use of metal-free, active, stable and inexpensive semiconductors that are capable of being used in a Z-scheme system for the conversion of $\mathrm{CO}_{2}$ was first introduced by Ishitani et al. in 2013. In a previous research study, it was reported that carbon nitride $\left(\mathrm{C}_{3} \mathrm{~N}_{4}\right)$ was successfully used as a photocatalyst for water reduction and oxidation. ${ }^{108}$ As a result, Ishitani et al. developed a hybrid photocatalyst consisting of a Ru-based metal complex (Table 8; 87) absorbed on graphitic $\mathrm{C}_{3} \mathrm{~N}_{4}\left(\mathrm{~g}-\mathrm{C}_{3} \mathrm{~N}_{4}\right)$. This hybrid system was able to reduce $\mathrm{CO}_{2}$ to FA photochemically with high selectivity $(>80 \%)$ and a $\mathrm{TON}_{\mathrm{FA}}$ of $>200$. However, a significant amount of hydrogen gas was also produced. ${ }^{109}$ 
Table 8 Homogeneous metal-based catalysts for $\mathrm{CO}_{2}$ to FA reduction linked to a metal-free semiconductor
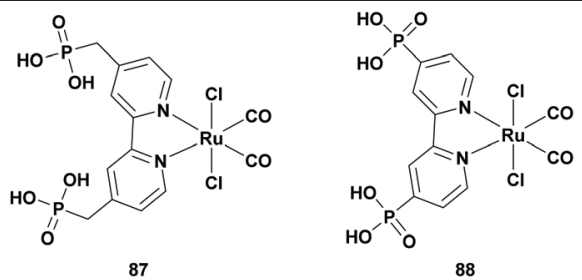

\begin{tabular}{|c|c|c|c|c|c|c|c|}
\hline Cat. & SC & Solv. & $\begin{array}{l}\text { Irr. t } \\
\text { (h) }\end{array}$ & $\begin{array}{l}\text { Sel. } \\
(\%)\end{array}$ & $\mathrm{TON}_{\mathrm{FA}}$ & $\begin{array}{l}\lambda \\
(\mathrm{nm})\end{array}$ & Ref. \\
\hline 87 & $\mathrm{~g}-\mathrm{C}_{3} \mathrm{~N}_{4}$ & $\mathrm{MeCN}$ & 20 & $>80$ & 200 & $>400$ & 109 \\
\hline 88 & $\mathrm{~g}-\mathrm{C}_{3} \mathrm{~N}_{4}$ & MeCN & 20 & $>80$ & 100 & 400 & 111 \\
\hline 88 & $\mathrm{~g}-\mathrm{C}_{3} \mathrm{~N}_{4}$ & DMA & 20 & $>80$ & 1070 & 400 & 111 \\
\hline 86 & $\mathrm{~g}-\mathrm{C}_{3} \mathrm{~N}_{4}$ & DMA & 5 & 52 & 43 & $>400$ & 112 \\
\hline 88 & $\mathrm{Ag}-\mathrm{g}-\mathrm{C}_{3} \mathrm{~N}_{4}$ & DMA & 5 & 98 & 1428 & $>400$ & 112 \\
\hline 86 & $\mathrm{Ag}-\mathrm{g}-\mathrm{C}_{3} \mathrm{~N}_{4}$ & DMA & 5 & $>99$ & 3110 & $>400$ & 112 \\
\hline 86 & Ag-g- $-\mathrm{C}_{3} \mathrm{~N}_{4}$ & $(\mathrm{COOK})_{2}$ & 15 & 83 & 586 & $>400$ & 112 \\
\hline 86 & $\mathrm{Ag}-\mathrm{NS}-\mathrm{C}_{3} \mathrm{~N}_{4}$ & $\mathrm{~K}_{2} \mathrm{CO}_{3}$ & 15 & 90 & 2090 & $>400$ & 113 \\
\hline 88 & $\mathrm{Ag}-\mathrm{g}-\mathrm{C}_{3} \mathrm{~N}_{4}$ & DMA & 5 & $>99$ & 650 & $>400$ & 116 \\
\hline
\end{tabular}

Cat. represents catalyst; SC represents semiconductor; Solv. represents solvent; Irr. t represents irradiation time; Sel. represents selectivity; $\mathrm{TON}_{\mathrm{FA}}$ represents turnover number for formic acid generation; $\lambda$ represents wavelength of the incoming radiation; Ref. represents reference; N.A. represents not applicable. Selectivities and TONs were determined after the corresponding irradiation times unless stated otherwise. $-=$ not mentioned.

Despite the promising use of this hybrid system as a photocatalyst for the reduction of $\mathrm{CO}_{2}$, no optimization studies were carried out. Later, Ishitani et al. improved their catalytic system by optimizing the Ru-based complex. Based on their previous report, ${ }^{110}$ they investigated different $\operatorname{trans}(\mathrm{Cl})$ $\left[\mathrm{Ru}\left(\mathrm{bpyX}_{2}\right)(\mathrm{CO})_{2} \mathrm{Cl}_{2}\right]$ complexes, where $\mathrm{X}=\mathrm{H}, \mathrm{Me}, \mathrm{PO}_{3} \mathrm{H}_{2}$ or $\mathrm{CH}_{2} \mathrm{PO}_{3} \mathrm{H}_{2}$. The RuP (Table 8; 88) and RuCP (Table 8; 87) complexes were absorbed quantitatively, whereas RuH and RuMe were not absorbed at all as they do not possess an anchoring group. The catalytic reactivity of these hybrid catalysts was investigated. In both of the cases, FA was selectively formed with the highest $\mathrm{TON}_{\mathrm{FA}}$ of approximately 200 for the $\mathrm{g}-\mathrm{C}_{3} \mathrm{~N}_{4}$ / RuP hybrid photocatalyst. Secondly, the effect of the solvent on the catalytic activity was investigated and the best result was obtained when DMA was used as the solvent $\left(\mathrm{TON}_{\mathrm{FA}}\right.$ of 1070). ${ }^{111}$

In the meantime, it was shown that supramolecular complexes exhibit higher reactivity. ${ }^{89-93}$ For this reason, Ishitani et al. continued their research based on the deposition of a supramolecular complex on the $\mathrm{g}-\mathrm{C}_{3} \mathrm{~N}_{4}$ semiconductor. When the binuclear RuRu' (Table 7; 86) complex was immobilized on g- $\mathrm{C}_{3} \mathrm{~N}_{4}$ and the resulting hybrid structure was used as a photocatalyst for the reduction of $\mathrm{CO}_{2}$, FA was produced in low selectivity (52\%) and with a lower $\mathrm{TON}_{\mathrm{FA}}$ (43) compared to the $\mathrm{RuP} / \mathrm{g}-\mathrm{C}_{3} \mathrm{~N}_{4}$ hybrid catalyst (Table 8). Furthermore, it was proven that the deposition of silver particles on a TaON semiconductor improved the catalytic activity. ${ }^{98}$ This concept was then employed for the $\mathrm{RuP} / \mathrm{C}_{3} \mathrm{~N}_{4}$ hybrid catalyst (Table 8; 88) and the RuCP/ $\mathrm{C}_{3} \mathrm{~N}_{4}$ hybrid catalyst (Table $8 ; 87$ ). It was found that $\mathrm{Ag}$ modification improved the reactivity of the RuP/Ag-g$\mathrm{C}_{3} \mathrm{~N}_{4}$ catalyst immensely and it also improved the selectivity to 98\%. An even higher increase in reactivity was observed using the $\mathrm{RuCP} / \mathrm{Ag}-\mathrm{g}-\mathrm{C}_{3} \mathrm{~N}_{4}$ catalyst. ${ }^{112}$

Ideally, heterogenized photocatalysts exhibit higher reactivity and selectivity in aqueous solutions, where water acts as a solvent and as an electron donor. Despite the excellent reactivity and selectivity of the binuclear complex RuRu' in DMA/ TEOA, the reduction in aqueous solutions was moderate with a selectivity of around $80 \%$ and a $\mathrm{TON}_{\mathrm{FA}}$ of $586 .{ }^{112}$ In 2017 , Ishitani et al. performed research on carbon nitride nanosheets $\left(\mathrm{NS}^{-} \mathrm{C}_{3} \mathrm{~N}_{4}\right)$ instead of graphitic carbon nitride. On this semiconductor, Ag was loaded and RuRu' (Table 7; 86) was absorbed. This hybrid catalyst, in the presence of EDTA.2Na solution ( $\mathrm{pH}$ 4.3), exhibited reactivity for the reduction of $\mathrm{CO}_{2}$ to $\mathrm{FA}$ with a selectivity of $76 \%$. Notably, when $\mathrm{NaH}_{2} \mathrm{PO}_{4}$ and $\mathrm{Na}_{2} \mathrm{HPO}_{4}$ were added, the $\mathrm{pH}$ increased to 6.1 and parallelly the reactivity and selectivity were also increased. The selectivity and activity were increased further $\left(\mathrm{TON}_{\mathrm{FA}}\right.$ of 2090) when the mixture had a pH between 6.5 and 7 (addition of $\mathrm{K}_{2} \mathrm{CO}_{3}$ ) (Table 8). However, the evolution of hydrogen decreased in neutral $\mathrm{pH}$ solutions. This $\mathrm{pH}$ dependency was explained by the fact that the semiconductor desorbed $\mathrm{RuRu}^{\prime}$ in more acidic environments, since the interaction between NS- ${ }_{3} \mathrm{~N}_{4}$ and RuRu' was based on hydrogen bonding. ${ }^{113}$

It was clear that silver species, deposited on semiconductors, promoted the photocatalytic reduction of $\mathrm{CO}_{2}$ with higher reactivity. It was explained that silver trapped electrons to mediate the charge transfer from the semiconductor to the photosensitizer unit of the RuRu' complex. However, the local structure of the loaded silver species in hybrid systems and its photocatalytic properties for $\mathrm{CO}_{2}$ reduction were not investigated in detail. Therefore, no guideline to improve the photocatalytic reactivity was available regarding the structure of the silver species. As a result, Ishitani et al. investigated the structure of silver-modified $\mathrm{NS}_{-} \mathrm{C}_{3} \mathrm{~N}_{4}$ to determine the impact on the photocatalytic reactivity of the loaded Ag-species. At first, they investigated silver-modified $\mathrm{NS}-\mathrm{C}_{3} \mathrm{~N}_{4}$ which was prepared by an impregnation- $\mathrm{H}_{2}$ reduction method of the RuP/ $\mathrm{Ag}-\mathrm{NS}-\mathrm{C}_{3} \mathrm{~N}_{4}$ hybrid catalyst. Here, the reactivity for the formation of formate was improved with the increase of $\mathrm{Ag}$ loading up to $2 \mathrm{wt} \%$ at an impregnation temperature of $473 \mathrm{~K}$. Moreover, the reactivity was strongly temperature dependent with the highest reactivity at an impregnation temperature of 473 K. Spectroscopic studies revealed that the silver particles were close in resemblance to $\mathrm{Ag}_{2} \mathrm{O}$ when a low amount of $\mathrm{Ag}$ was loaded on the semiconductor, but metallic silver particles were more pronounced when a larger amount was loaded on the semiconductor. Moreover, the impregnation temperature determines the form as well, where higher temperatures yield more metallic silver particles. Thus, in the case of the $2 \mathrm{wt} \%$ impregnation $-\mathrm{H}_{2}$ reduction method at $473 \mathrm{~K}, \mathrm{Ag}_{2} \mathrm{O}$ was dominant, whereas in the $2 \mathrm{wt} \%$ impregnation $-\mathrm{H}_{2}$ reduction method at $623 \mathrm{~K}, \mathrm{Ag}^{0}$ was formed to a greater extent. It was also shown that a higher dispersion enhanced the reactivity, 
while aggregates or excess of $\mathrm{Ag}^{0}$-particles provided lower reactivity. However, whether $\mathrm{Ag}^{0}$ had a positive effect on the reactivity could not have been drawn here. Therefore, further experiments were performed, where silver-modified $\mathrm{NS}^{-} \mathrm{C}_{3} \mathrm{~N}_{4}$ was prepared from impregnation-air heating (minimalize $\mathrm{Ag}^{0}$ formation) or where it was prepared from in situ photodeposition $\left(\mathrm{Ag}^{0}\right.$ has to be dominant). Both of the samples were used for the reduction of $\mathrm{CO}_{2}$ when RuP was absorbed and both provided lower reactivity. However, the sample prepared via photodeposition (widely distributed $\mathrm{Ag}^{0}$ ) was much more reactive than the sample prepared via the $\mathrm{H}_{2}$ reduction method at $623 \mathrm{~K}$ (dispersedly divided $\mathrm{Ag}^{0}+\mathrm{Ag}_{2} \mathrm{O}$ ). This result indicated that $\mathrm{Ag}^{0}$ had a better promotional effect than $\mathrm{Ag}_{2} \mathrm{O}$-like species. As a result, finely dispersed $\mathrm{Ag}^{0}$ species would be key to promote the activity of hybrid systems. ${ }^{114}$

Synthetic procedures for the preparation of $\mathrm{C}_{3} \mathrm{~N}_{4}$ usually require hard-template methods with multistep procedures. For this reason, the desire of synthesizing carbon nitride in a more effective and less expensive way is of great interest. It was shown by Chen et al. that $\mathrm{g}-\mathrm{C}_{3} \mathrm{~N}_{4}$ could be synthesized from the pyrolysis of urea. ${ }^{115}$ In fact it had been proven that ureaderived $\mathrm{C}_{3} \mathrm{~N}_{4}$ showed improved reactivity for the reduction of $\mathrm{CO}_{2} \cdot{ }^{113}$ However, thermal decomposition of urea to form $\mathrm{C}_{3} \mathrm{~N}_{4}$ at different temperatures should affect its physicochemical properties, which has not been studied before. Therefore, research was performed on this topic by Ishitani et al. by synthesizing urea at different temperatures for the photocatalytic reduction of $\mathrm{CO}_{2}$ when RuP was added as the catalyst. Spectroscopic techniques exhibited an increase of crystallized $\mathrm{C}_{3} \mathrm{~N}_{4}$ formation at higher temperatures. However, at elevated temperatures, the formed $\mathrm{C}_{3} \mathrm{~N}_{4}$ decomposed. It was also found that at $773 \mathrm{~K}$ a lot of voids were formed in the graphitic structure, whereas a nanosheet-like structure was formed at $823 \mathrm{~K}$ or higher temperatures. Afterwards, photoreductions were carried out using the synthesized $\mathrm{C}_{3} \mathrm{~N}_{4}$ structures at different temperatures in a TEOA/DMA solvent mixture. Here, $\mathrm{Ag}$ was deposited and the RuP (Table 8; 88) catalyst was absorbed on the semiconductor. With an increase in the deposition temperature, more formate was formed with a maximum $\mathrm{TON}_{\mathrm{FA}}$ of 650 at $873-923 \mathrm{~K}$. The catalytic reactivity was explained by the structure of the synthesized $\mathrm{C}_{3} \mathrm{~N}_{4}$ : the $\mathrm{C}_{3} \mathrm{~N}_{4}$ at elevated temperatures absorbed visible light better and had a higher specific surface area for the catalyst and Ag dispersion. ${ }^{116}$

As stated before, heterogeneous catalysts have the main advantage that they can be recycled and used in subsequent reactions. When metal-free semiconductors are used, the economic advantage increases even more, since metal-free semiconductors are generally cheaper compared to their metal counterparts. From the reported procedures, it can be concluded that $\mathrm{g}-\mathrm{C}_{3} \mathrm{~N}_{4}$ is an extremely viable semi-conductor for the photocatalytic reduction of $\mathrm{CO}_{2}$ to FA. Specifically, when it is doped with Ag-particles, the $\mathrm{TON}_{\mathrm{FA}}$ is comparable with mononuclear Ru-complexes. Since the concept of using $\mathrm{C}_{3} \mathrm{~N}_{4}$ is relatively new, many reports are expected in the future.

\section{Conclusion and outlook}

$\mathrm{CO}_{2}$ photoreduction to FA using transition metal complexes has been summarized in this review. From the discussion, it is clear that visible light promoted $\mathrm{CO}_{2}$ reductions to $\mathrm{FA}$ has become a topic of great interest in green chemistry. The use of ruthenium-based metal complexes as homogeneous catalysts has been well-explored. Although great TONs for the production of $\mathrm{HCOOH}$ could be observed, scientists searched for Earth abundant metal complexes such as Co-, Mn-, Fe- and Mb-based catalysts, as well as metal-free catalysts. Furthermore, it was shown that photoreductions only proceeded in the presence of a photosensitizer. This led to the linkage of a photosensitiser and a catalyst in a supramolecular complex, which resulted in higher activities since electron exchange from the photosensitizer to the catalyst was facilitated.

In addition, this review shows that heterogeneous photocatalysts are desirable for the photoreduction of $\mathrm{CO}_{2}$ to $\mathrm{FA}$ as recyclable catalysts in green chemistry. ${ }^{117,118}$ Here, silverdoped semiconductors linked to supramolecular complexes in a Z-scheme heterojunction are the most noteworthy catalysts. Although the visible-light promoted reduction of $\mathrm{CO}_{2}$ to FA by (heterogenized) homogeneous catalysis has made excellent progress over the last few decades, only a few cases yielded TON $_{\mathrm{FA}}$ values greater than 1000 and still, a lot of metal complexes remain unexplored for this application. We hope that this review will encourage scientists to design new homogeneous metal complexes and explore these complexes in the visible-light promoted $\mathrm{CO}_{2}$ reduction to FA. Additionally, we hope that the heterogenized concept discussed in this review will inspire chemists to develop and explore new functionalised semiconductors. Moreover, the efforts will also be not limited to metal-based complexes, rather they will also focus on some metal-free catalysts owing to their cheaper price and easy availability. ${ }^{119-135}$

Although extensive efforts are being made to achieve high reactivity, metal-based catalysts still have some drawbacks. Firstly, the reported results vary immensely, even when the same metal centre has been used. As a result, it is impossible to establish a general structure-activity relationship on which researchers can rely in the future. Secondly, many of the reported catalysts lose reactivity under the photocatalytic conditions, since they are not stable enough. Thirdly, the reported catalytic systems are not sustainable and economically feasible to perform on a larger scale. Fourthly, the use of heterogenized catalysts requires the diffusion of $\mathrm{CO}_{2}$ through the catalysts. Up to now, no study has been performed on the adsorption behaviour of $\mathrm{CO}_{2}$ in these catalysts. Finally, in general, the systems are not efficient enough in terms of activity and selectivity.

To overcome the abovementioned problems, extensive research studies on the photocatalytic reduction of $\mathrm{CO}_{2}$ to $\mathrm{FA}$ have to be performed in the coming years. One way of doing so is by varying the PC in the catalytic systems. In such a way, efficient cycles can be found. Additionally, this can provide a 
better understanding of the structure-activity relationship of the used catalysts for the photoreduction of $\mathrm{CO}_{2}$ to FA. Another way is the development of new PSs, especially, Earth abundant metal based PSs, based on organic molecules and inorganic semiconductors. In this way, the absorption of visible light can be enhanced allowing the optimum use of the incident energy. Secondly, the stability of the catalytic system can be examined by performing recycling experiments. Additionally, by using ${ }^{13} \mathrm{CO}_{2}$, the carbon source of FA can be verified, since the catalyst or other organic materials in the catalytic system can decompose themselves. Thirdly, the photocatalytic systems should be optimised to avoid sacrificial electron donors such as TEOA or BIH. This can be done by coupling the system to the formation of value added organic compounds via an oxidation process or by the coupling of the system to water oxidation. In fact, the coupling of $\mathrm{CO}_{2}$ reduction with $\mathrm{H}_{2} \mathrm{O}$ oxidation has already been performed by $\mathrm{Li}$ et al. when using heterogeneous $\mathrm{Cu}_{2} \mathrm{O}-\mathrm{Pt} / \mathrm{SiC} / \mathrm{IrO}_{x}$ composites with excellent efficiency. ${ }^{136}$ In summary, extensive research studies on the photocatalytic reduction of $\mathrm{CO}_{2}$ to FA have great potential to achieve high activities and selectivities in a sustainable and economically favourable way.

\section{Conflicts of interest}

There are no conflicts to declare.

\section{Acknowledgements}

We thank Fond der Chemie Industrie (Liebig fellowship to $\mathrm{SD})$, Francqui Foundation (Francqui lecturer award to SD) and Dehausse fellowship (to RC). Special thanks to Dr Yu Zhang and Mr Tong Zhang for their kind help during the preparation of this manuscript.

\section{Notes and references}

1 T. A. Carleton and S. M. Hsiang, Science, 2016, 353, aad 9837.

2 https://www.iea.org/reports/global-energy-co2-status-report2019.

3 M. Bui, C. S. Adjiman, A. Bardow, E. J. Anthony, A. Boston, S. Brown, P. S. Fennell, S. Fuss, A. Galindo, L. A. Hackett, J. P. Hallett, H. J. Herzog, G. Jackson, J. Kemper, S. Krevor, G. C. Maitland, M. Matuszewski, I. S. Metcalfe, C. Petit, G. Puxty, J. Reimer, D. M. Reiner, E. S. Rubin, S. A. Scott, N. Shah, B. Smit, J. P. M. Trusler, P. Webley, J. Wilcox and N. Mac Dowell, Energy Environ. Sci., 2018, 11, 1062.

4 J. Tollefson, Nature, 2018, 558, 173.

5 S. Sorcar, J. Thompson, Y. Hwang, Y. H. Park, T. Majima, C. A. Grimes, J. R. Durrant and S.-I. In, Energy Environ. Sci., 2018, 11, 3183.

6 Q. Liu, L. Wu, R. Jackstell and M. Beller, Nat. Commun., 2015, 6, 5933.
7 https://setis.ec.europa.eu/related-jrc-activities/jrc-setis-reports/ carbon-capture-and-storage-technology-information-sheet.

8 H. Seo, M. H. Katcher and T. F. Jamison, Nat. Chem., 2017, 9, 453.

9 M. Aresta, A. Dibenedetto and A. Angelini, Chem. Rev., 2014, 114, 1709.

10 S. Ye, C. Ding, R. Chen, F. Fan, P. Fu, H. Yin, X. Wang, Z. Wang, P. Du and C. Li, J. Am. Chem. Soc., 2018, 140, 3250.

11 P. F. Wareing, M. M. Khalifa and K. J. Treharne, Nature, 1968, 220(5166), 453.

12 Y. Wang, J. Liu, Y. Wang, Y. Wang and G. Zheng, Nat. Commun., 2018, 9, 5003.

13 D. M. Schultz and T. P. Yoon, Science, 2014, 343, 1239176.

14 R. J. Detz, J. N. H. Reek and B. C. C. van der Zwaan, Energy Environ. Sci., 2018, 11, 1653.

15 S. Lin, C. S. Diercks, Y.-B. Zhang, N. Kornienko, E. M. Nichols, Y. Zhao, A. R. Paris, D. Kim, P. Yang, O. M. Yaghi and C. J. Chang, Science, 2015, 349, 1208.

16 J. J. Leung, J. Warnan, K. H. Ly, N. Heidary, D. H. Nam, M. F. Kuehnel and E. Reisner, Nat. Catal., 2019, 2, 354.

17 A. K. Singh, J. H. Montoya, J. M. Gregoire and K. A. Persson, Nat. Commun., 2019, 10, 443.

18 X. Li, Y. Sun, J. Xu, Y. Shao, J. Wu, X. Xu, Y. Pan, H. Ju, J. Zhu and Y. Xie, Nat. Energy, 2019, 4, 690.

19 J. L. White, M. F. Baruch, J. E. Pander, Y. Hu, I. C. Fortmeyer, J. E. Park, T. Zhang, K. Liao, J. Gu, Y. Yan, T. W. Shaw, E. Abelev and A. B. Bocarsly, Chem. Rev., 2015, 115, 12888.

20 S. Sato, T. Arai, T. Morikawa, K. Uemura, T. M. Suzuki, H. Tanaka and T. Kajino, J. Am. Chem. Soc., 2011, 133, 15240.

21 K. Sekizawa, K. Maeda, K. Domen, K. Koike and O. Ishitani, J. Am. Chem. Soc., 2013, 135, 4596.

22 S. Matsuoka, K. Yamamoto, T. Ogata, M. Kusaba, N. Nakashima, E. Fujita and S. Yanagida, J. Am. Chem. Soc., 1993, 115, 601.

23 S. Moret, P. J. Dyson and G. Laurenczy, Nat. Commun., 2014, 5, 4017.

24 A. Boddien, D. Mellmann, F. Gärtner, R. Jackstell, H. Junge, P. J. Dyson, G. Laurenczy, R. Ludwig and M. Beller, Science, 2011, 333, 1733.

25 D. Mellmann, P. Sponholz, H. Junge and M. Beller, Chem. Soc. Rev., 2016, 45, 3954.

26 C. Fellay, P. J. Dyson and G. Laurenczy, Angew. Chem., Int. Ed., 2008, 47, 3966.

27 https://www.mordorintelligence.com/industry-reports/formicacid-market.

28 U. Fegade and G. Jethave, in Conversion of Carbon Dioxide into Hydrocarbons Vol. 2 Technology, ed. Inamuddin, A. M. Asiri and E. Lichtfouse, Springer International Publishing, Cham, 2020, pp. 91-110, DOI: 10.1007/978-3030-28638-5_4.

29 E. Fujita, Coord. Chem. Rev., 1999, 185-186, 373. 
30 T. Inoue, A. Fujishima, S. Konishi and K. Honda, Nature, 1979, 277, 637.

31 N. Li, J. Liu, J.-J. Liu, L.-Z. Dong, Z.-F. Xin, Y.-L. Teng and Y.-Q. Lan, Angew. Chem., Int. Ed., 2019, 58, 5280.

32 D. Wang, R. Huang, W. Liu, D. Sun and Z. Li, ACS Catal., 2014, 4, 4254.

33 Z.-H. Yan, M.-H. Du, J. Liu, S. Jin, C. Wang, G.-L. Zhuang, X.-J. Kong, L.-S. Long and L.-S. Zheng, Nat. Commun., 2018, 9, 3353.

34 J. Hawecker, J.-M. Lehn and R. Ziessel, ChemComm, 1983, 536, DOI: 10.1039/C39830000536.

35 J. Hawecker, J.-M. Lehn and R. Ziessel, ChemComm, 1985, 56, DOI: $10.1039 / \mathrm{C} 39850000056$.

36 J.-M. Lehn and R. Ziessel, J. Organomet. Chem., 1990, 382, 157.

37 H. Ishida, T. Terada, K. Tanaka and T. Tanaka, Inorg. Chem., 1990, 29, 905.

38 J. R. Pugh, M. R. M. Bruce, B. P. Sullivan and T. J. Meyer, Inorg. Chem., 1991, 30, 86.

39 A. Paul, D. Connolly, M. Schulz, M. T. Pryce and J. G. Vos, Inorg. Chem., 2012, 51, 1977.

40 Y. Kuramochi, M. Kamiya and H. Ishida, Inorg. Chem., 2014, 53, 3326.

41 Y. Kuramochi, J. Itabashi, K. Fukaya, A. Enomoto, M. Yoshida and H. Ishida, Chem. Sci., 2015, 6, 3063.

42 A. Rosas-Hernández, H. Junge and M. Beller, ChemCatChem, 2015, 7, 3316.

43 T. Morimoto, C. Nishiura, M. Tanaka, J. Rohacova, Y. Nakagawa, Y. Funada, K. Koike, Y. Yamamoto, S. Shishido, T. Kojima, T. Saeki, T. Ozeki and O. Ishitani, J. Am. Chem. Soc., 2013, 135, 13266.

44 T. Asatani, Y. Nakagawa, Y. Funada, S. Sawa, H. Takeda, T. Morimoto, K. Koike and O. Ishitani, Inorg. Chem., 2014, 53, 7170.

45 J. Rohacova, A. Sekine, T. Kawano, S. Tamari and O. Ishitani, Inorg. Chem., 2015, 54, 8769.

46 J. Rohacova and O. Ishitani, Chem. Sci., 2016, 7, 6728.

47 S. K. Lee, M. Kondo, G. Nakamura, M. Okamura and S. Masaoka, ChemComm, 2018, 54, 6915.

48 S. K. Lee, M. Kondo, M. Okamura, T. Enomoto, G. Nakamura and S. Masaoka, J. Am. Chem. Soc., 2018, 140, 16899.

49 Y. Hameed, G. K. Rao, J. S. Ovens, B. Gabidullin and D. Richeson, ChemSusChem, 2019, 12, 3453.

50 Y. Arikawa, T. Nakamura, S. Ogushi, K. Eguchi and K. Umakoshi, Dalton Trans., 2015, 44, 5303.

51 Y. Arikawa, I. Tabata, Y. Miura, H. Tajiri, Y. Seto, S. Horiuchi, E. Sakuda and K. Umakoshi, Chem. - Eur. J., 2020, 26, 5603.

52 D. Behar, T. Dhanasekaran, P. Neta, C. M. Hosten, D. Ejeh, P. Hambright and E. Fujita, J. Phys. Chem. A, 1998, 102, 2870.

53 D. Lexa, J. M. Savéant and J. P. Soufflet, J. Electroanal. Chem. Interfacial Electrochem., 1979, 100, 159.

54 J. Grodkowski and P. Neta, J. Phys. Chem. A, 2000, 104, 1848.
55 Z. Guo, G. Chen, C. Cometto, B. Ma, H. Zhao, T. Groizard, L. Chen, H. Fan, W.-L. Man, S.-M. Yiu, K.-C. Lau, T.-C. Lau and M. Robert, Nat. Catal., 2019, 2, 801.

56 M. Bourrez, F. Molton, S. Chardon-Noblat and A. Deronzier, Angew. Chem., Int. Ed., 2011, 50, 9903.

57 H. Takeda, H. Koizumi, K. Okamoto and O. Ishitani, ChemComm, 2014, 50, 1491.

58 P. L. Cheung, C. W. Machan, A. Y. S. Malkhasian, J. Agarwal and C. P. Kubiak, Inorg. Chem., 2016, 55, 3192.

59 M. Stanbury, J.-D. Compain, M. Trejo, P. Smith, E. Gouré and S. Chardon-Noblat, Electrochim. Acta, 2017, 240, 288.

60 J.-X. Zhang, C.-Y. Hu, W. Wang, H. Wang and Z.-Y. Bian, Appl. Catal., A, 2016, 522, 145.

61 X. Zhang, M. Cibian, A. Call, K. Yamauchi and K. Sakai, ACS Catal., 2019, 9, 11263-11273.

62 H. Takeda, H. Kamiyama, K. Okamoto, M. Irimajiri, T. Mizutani, K. Koike, A. Sekine and O. Ishitani, J. Am. Chem. Soc., 2018, 140, 17241.

63 L. Chen, Z. Guo, X.-G. Wei, C. Gallenkamp, J. Bonin, E. Anxolabéhère-Mallart, K.-C. Lau, T.-C. Lau and M. Robert, J. Am. Chem. Soc., 2015, 137, 10918.

64 T. Fogeron, T. K. Todorova, J.-P. Porcher, M. GomezMingot, L.-M. Chamoreau, C. Mellot-Draznieks, Y. Li and M. Fontecave, ACS Catal., 2018, 8, 2030.

65 T. Fogeron, P. Retailleau, L.-M. Chamoreau, Y. Li and M. Fontecave, Angew. Chem., Int. Ed., 2018, 57, 17033.

66 S. Sato, T. Morikawa, T. Kajino and O. Ishitani, Angew. Chem., Int. Ed., 2013, 52, 988.

67 S. Sato and T. Morikawa, ChemPhotoChem, 2018, 2, 207.

68 Y.-H. Luo, L.-Z. Dong, J. Liu, S.-L. Li and Y.-Q. Lan, Coord. Chem. Rev., 2019, 390, 86-126.

69 K. Kamada, J. Jung, T. Wakabayashi, K. Sekizawa, S. Sato, T. Morikawa, S. Fukuzumi and S. Saito, J. Am. Chem. Soc., 2020, 142, 10261.

70 J. Hawecker, J.-M. Lehn and R. Ziessel, J. Chem. Soc., Chem. Commun., 1983, 536-538, DOI: 10.1039/ C39830000536.

71 Y. Hameed, P. Berro, B. Gabidullin and D. Richeson, ChemComm, 2019, 55, 11041.

72 S. Matsuoka, H. Fujii, C. Pac and S. Yanagida, Chem. Lett., 1990, 19, 1501.

73 S. Tazuke and H. Ozawa, ChemComm, 1975, 237, DOI: 10.1039/C39750000237.

74 S. Matsuoka, T. Kohzuki, C. Pac and S. Yanagida, Chem. Lett., 1990, 19, 2047.

75 B. J. Fisher and R. Eisenberg, J. Am. Chem. Soc., 1980, 102, 7361.

76 S. Matsuoka, K. Yamamoto, C. Pac and S. Yanagida, Chem. Lett., 1991, 20, 2099.

77 J.-M. Lehn and R. Ziessel, Proc. Natl. Acad. Sci. U. S. A., 1982, 79, 701-704.

78 T. Hideyuki, O. Masatoshi, T. Yoshiki, W. Yoshinori, K. Masa and C. Koji, Bull. Chem. Soc. Jpn., 1990, 63, 3233.

79 I. Willner and D. Mandler, J. Am. Chem. Soc., 1989, 111, 1330. 
80 T. Ogata, Y. Yamamoto, Y. Wada, K. Murakoshi, M. Kusaba, N. Nakashima, A. Ishida, S. Takamuku and S. Yanagida, J. Phys. Chem., 1995, 99, 11916.

81 D. J. Boston, C. Xu, D. W. Armstrong and F. M. MacDonnell, J. Am. Chem. Soc., 2013, 135, 16252.

82 A. M. Appel, J. E. Bercaw, A. B. Bocarsly, H. Dobbek, D. L. DuBois, M. Dupuis, J. G. Ferry, E. Fujita, R. Hille, P. J. A. Kenis, C. A. Kerfeld, R. H. Morris, C. H. F. Peden, A. R. Portis, S. W. Ragsdale, T. B. Rauchfuss, J. N. H. Reek, L. C. Seefeldt, R. K. Thauer and G. L. Waldrop, Chem. Rev., 2013, 113, 6621.

83 Z. Han, W. R. McNamara, M.-S. Eum, P. L. Holland and R. Eisenberg, Angew. Chem., Int. Ed., 2012, 51, 1667.

84 Z. Han, L. Shen, W. W. Brennessel, P. L. Holland and R. Eisenberg, J. Am. Chem. Soc., 2013, 135, 14659.

85 S. E. Lee, A. Nasirian, Y. E. Kim, P. T. Fard, Y. Kim, B. Jeong, S.-J. Kim, J.-O. Baeg and J. Kim, J. Am. Chem. Soc., 2020, 142, 19142.

86 H. Takeda and O. Ishitani, Coord. Chem. Rev., 2010, 254, 346.

87 S. Sato, K. Koike, H. Inoue and O. Ishitani, Photochem. Photobiol. Sci., 2007, 6, 454.

88 Y. Tamaki, K. Watanabe, K. Koike, H. Inoue, T. Morimoto and O. Ishitani, Faraday Discuss., 2012, 155, 115.

89 A. Nakada, K. Koike, T. Nakashima, T. Morimoto and O. Ishitani, Inorg. Chem., 2015, 54, 1800.

90 Y. Tamaki, T. Morimoto, K. Koike and O. Ishitani, Proc. Natl. Acad. Sci. U. S. A., 2012, 109, 15673.

91 Y. Tamaki, K. Koike and O. Ishitani, Chem. Sci., 2015, 6, 7213.

92 Y. Tamaki and O. Ishitani, Faraday Discuss., 2017, 198, 319.

93 D. C. Fabry, H. Koizumi, D. Ghosh, Y. Yamazaki, H. Takeda, Y. Tamaki and O. Ishitani, Organometallics, 2020, 39, 1511.

94 S. Sato, T. Morikawa, S. Saeki, T. Kajino and T. Motohiro, Angew. Chem., Int. Ed., 2010, 49, 5101.

95 T. M. Suzuki, H. Tanaka, T. Morikawa, M. Iwaki, S. Sato, S. Saeki, M. Inoue, T. Kajino and T. Motohiro, ChemComm, 2011, 47, 8673.

96 M. S. Wrighton, A. B. Ellis, P. T. Wolczanski, D. L. Morse, H. B. Abrahamson and D. S. Ginley, J. Am. Chem. Soc., 1976, 98, 2774.

97 T. Arai, S. Sato, T. Kajino and T. Morikawa, Energy Environ. Sci., 2013, 6, 1274.

98 F. Yoshitomi, K. Sekizawa, K. Maeda and O. Ishitani, ACS Appl. Mater. Interfaces, 2015, 7, 13092.

99 M. Liu, W. You, Z. Lei, G. Zhou, J. Yang, G. Wu, G. Ma, G. Luan, T. Takata, M. Hara, K. Domen and C. Li, ChemComm, 2004, 2192, DOI: 10.1039/B407892F.

100 K. Muraoka, H. Kumagai, M. Eguchi, O. Ishitani and K. Maeda, ChemComm, 2016, 52, 7886.

101 A. Nakada, R. Kuriki, K. Sekizawa, S. Nishioka, J. J. M. Vequizo, T. Uchiyama, N. Kawakami, D. Lu, A. Yamakata, Y. Uchimoto, O. Ishitani and K. Maeda, ACS Catal., 2018, 8, 9744.
102 R. Kuriki, T. Ichibha, K. Hongo, D. Lu, R. Maezono, H. Kageyama, O. Ishitani, K. Oka and K. Maeda, J. Am. Chem. Soc., 2018, 140, 6648.

103 T. Oshima, T. Ichibha, K. S. Qin, K. Muraoka, J. J. M. Vequizo, K. Hibino, R. Kuriki, S. Yamashita, K. Hongo, T. Uchiyama, K. Fujii, D. Lu, R. Maezono, A. Yamakata, H. Kato, K. Kimoto, M. Yashima, Y. Uchimoto, M. Kakihana, O. Ishitani, H. Kageyama and K. Maeda, Angew. Chem., Int. Ed., 2018, 57, 8154.

104 A. Ishikawa, T. Takata, T. Matsumura, J. N. Kondo, M. Hara, H. Kobayashi and K. Domen, J. Phys. Chem. B, 2004, 108, 2637.

105 H. Tatsumi, K. Teramura, Z. Huang, Z. Wang, H. Asakura, S. Hosokawa and T. Tanaka, Langmuir, 2017, 33, 13929.

106 K. Muraoka, M. Eguchi, O. Ishitani, F. Cheviré and K. Maeda, J. Energy Chem., 2021, 55, 176.

107 K. Muraoka, T. Uchiyama, D. Lu, Y. Uchimoto, O. Ishitani and K. Maeda, Bull. Chem. Soc. Jpn., 2019, 92, 124.

108 K. Maeda, X. Wang, Y. Nishihara, D. Lu, M. Antonietti and K. Domen, J. Phys. Chem. C, 2009, 113, 4940.

109 K. Maeda, K. Sekizawa and O. Ishitani, ChemComm, 2013, 49, 10127.

110 H. Takeda, K. Koike, H. Inoue and O. Ishitani, J. Am. Chem. Soc., 2008, 130, 2023.

111 R. Kuriki, K. Sekizawa, O. Ishitani and K. Maeda, Angew. Chem., Int. Ed., 2015, 54, 2406.

112 R. Kuriki, H. Matsunaga, T. Nakashima, K. Wada, A. Yamakata, O. Ishitani and K. Maeda, J. Am. Chem. Soc., 2016, 138, 5159.

113 R. Kuriki, M. Yamamoto, K. Higuchi, Y. Yamamoto, M. Akatsuka, D. Lu, S. Yagi, T. Yoshida, O. Ishitani and K. Maeda, Angew. Chem., Int. Ed., 2017, 56, 4867.

114 K. Maeda, D. An, C. S. Kumara Ranasinghe, T. Uchiyama, R. Kuriki, T. Kanazawa, D. Lu, S. Nozawa, A. Yamakata, Y. Uchimoto and O. Ishitani, J. Mater. Chem. A, 2018, 6, 9708.

115 J. Liu, T. Zhang, Z. Wang, G. Dawson and W. Chen, J. Mater. Chem., 2011, 21, 14398.

116 K. Maeda, D. An, R. Kuriki, D. Lu and O. Ishitani, Beilstein J. Org. Chem., 2018, 14, 1806.

117 A. Karakulina, A. Gopakumar, İ. Akçok, B. L. Roulier, T. LaGrange, S. A. Katsyuba, S. Das and P. J. Dyson, Angew. Chem., Int. Ed., 2016, 55, 292.

118 Y. Zhang, N. Hatami, N. S. Lange, E. Ronge, W. Schilling, C. Jooss and S. Das, Green Chem., 2020, 22, 4516.

119 P. Hirapara, D. Riemer, N. Hazra, J. Gajera, M. Finger and S. Das, Green Chem., 2017, 19, 5356.

120 D. Riemer, P. Hirapara and S. Das, ChemSusChem, 2016, 9, 1916.

121 D. Riemer, B. Mandaviya, W. Schilling, A. C. Götz, T. Kühl, M. Finger and S. Das, ACS Catal., 2018, 8, 3030.

122 W. Schilling and S. Das, ChemSusChem, 2020, 13, 6246.

123 F. D. Bobbink, S. Das and P. J. Dyson, Nat. Protoc., 2017, $12,417$.

124 S. Das, Y. Li, L.-Q. Lu, K. Junge and M. Beller, Chem. Eur. J., 2016, 22, 7050. 
125 W. Schilling and S. Das, Tetrahedron Lett., 2018, 59, 3821.

126 Y. Zhang, T. Zhang and S. Das, Green Chem., 2020, 22, 1800.

127 M. Hulla, S. M. A. Chamam, G. Laurenczy, S. Das and P. J. Dyson, Angew. Chem., Int. Ed., 2017, 56, 10559.

128 D. Riemer, W. Schilling, A. Goetz, Y. Zhang, S. Gehrke, I. Tkach, O. Hollóczki and S. Das, ACS Catal., 2018, 8, 11679.

129 Y. Zhang, D. Riemer, W. Schilling, J. Kollmann and S. Das, ACS Catal., 2018, 8, 6659.

130 W. Schilling, D. Riemer, Y. Zhang, N. Hatami and S. Das, ACS Catal., 2018, 8, 5425.
131 J. Kollmann, Y. Zhang, W. Schilling, T. Zhang, D. Riemer and S. Das, Green Chem., 2019, 21, 1916.

132 T. Zhang, Y. Zhang and S. Das, ChemCatChem, 2020, 12, 6173.

133 Y. Zhang, W. Schilling, D. Riemer and S. Das, Nat. Protoc., 2020, 15, 822.

134 W. Schilling, Y. Zhang, D. Riemer and S. Das, Chem. - Eur. J., 2020, 26, 390.

135 Y. Zhang, W. Schilling and S. Das, ChemSusChem, 2019, $12,2898$.

136 Y. Wang, X. Shang, J. Shen, Z. Zhang, D. Wang, J. Lin, J. C. S. Wu, X. Fu, X. Wang and C. Li, Nat. Commun., 2020, 11, 3043 . 